\title{
JOVENS E ADULTOS COM BAIXA ESCOLARIDADE, OFERTA DE EJA E DESIGUALDADES NAS CHANCES DE CONCLUSÃO DO ENSINO FUNDAMENTAL E DO MÉDIO*
}

\author{
Robson dos Santos ${ }^{\mathrm{I}}$
}

http://dx.doi.org/10.24109/9788578630669.ceppe.vla5

\section{RESUMO}

Este estudo analisa as características de jovens e adultos que não frequentam a escola e não possuem o ensino fundamental ou a educação básica completa, tendo como referência os públicos das Metas 8, 9 e 10 do Plano Nacional de Educação (PNE). Aborda a educação de jovens e adultos (EJA) e a aprendizagem ao longo da vida como referências para a análise de políticas voltadas à concretização do direito à educação; apresenta a distribuição dos sujeitos fora da escola em situação de baixa escolaridade, destacando os grupos nos quais o fenômeno é prevalente; descreve os números de escolas e matrículas em EJA e o perfil etário dessas matrículas; e, a partir de modelos de regressão logística binária, investiga as desigualdades nas chances de conclusão da educação básica e do ensino fundamental, considerando o rendimento domiciliar, o sexo, o local de residência, a raça/cor e a ocupação. Os resultados gerais apontam que: a demanda por educação de

\footnotetext{
* Resultados parciais deste trabalho foram apresentados em seminário sobre o Plano Nacional de Educação realizado no Ministério da Educação e no Seminário "Indicadores Educacionais e o Monitoramento do Plano Nacional de Educação”, realizado no Instituto Nacional de Estudos e Pesquisas Educacionais, entre os dias 28 e 29 de novembro de 2017.

I Robson dos Santos é doutor em sociologia pela Universidade Estadual de Campinas (Unicamp) e pesquisador do Instituto Nacional de Estudos e Pesquisas Educacionais Anísio Teixeira (Inep), atuando na Diretoria de Estudos Educacionais (Dired).
} 
jovens e adultos não consiste em um fenômeno centrado nas coortes mais velhas, pois, mesmo entre os grupos mais jovens, são elevados os percentuais dos que não frequentam a escola e não possuem a educação básica ou, ao menos, o ensino fundamental completo; o número de estabelecimentos de ensino que oferecem a EJA diminuiu entre 2014 e 2017, principalmente em escolas com localização rural; as matrículas em EJA, em 2016, concentravam-se, tanto no ensino fundamental como no médio, entre os grupos de menor idade, com baixa participação de sujeitos acima dos 35 anos; em 2015, existiam desigualdades significativas nas chances de conclusão do ensino fundamental e da educação básica, em prejuízo para os jovens do sexo masculino, os residentes no campo, os de menor renda, os negros e os sem ocupação.

Palavras-chave: desigualdades educacionais; direito à educação; EJA; PNE.

\section{INTRODUÇÃO}

O Plano Nacional de Educação (PNE), Lei n $\mathrm{n}^{0} 13.005$ de 2014, tem a finalidade de induzir políticas e processos educacionais voltados à redução das desigualdades escolares, ao enfrentamento das disparidades sociais e à qualificação do exercício da cidadania. Isso fica expresso, principalmente, em três de suas diretrizes (artigo $2^{\circ}$ ), nomeadamente as que objetivam: a erradicação do analfabetismo; a superação das desigualdades educacionais, com ênfase na promoção da cidadania e na erradicação de todas as formas de discriminação; e a promoção dos princípios do respeito aos direitos humanos, à diversidade e à sustentabilidade socioambiental.

As referidas diretrizes, que podem ser tomadas como macro objetivos a perpassar todo o documento, são transversais e se espraiam pelas 20 metas e pelas respectivas estratégias que compõe o Plano. As Metas 8, 9 e 10, especificamente, rementem à concretização do direito à educação para as populações jovens e adultas que não a obtiveram em momentos anteriores de sua trajetória. A Meta 8 estabelece a necessidade de que os sujeitos entre 18 e 29 anos de idade, considerados em sua pluralidade sociocultural e territorial, tenham acesso às políticas que elevem sua escolaridade média para 12 anos de estudo, até o ano de 2024. A Meta 9 se concentra no analfabetismo funcional e no absoluto, propondo reduzir o primeiro a $50 \%$ do que foi registrado pelas pesquisas disponíveis à época de lançamento do PNE e zerar o segundo até o final do Plano, tendo como foco a população com 15 anos ou mais de idade. Já a Meta 10 se volta para a elevação da escolaridade de jovens e adultos, mediante a ampliação do número de matrículas em educação de jovens e adultos (EJA) integradas à educação profissional. 
Essas três metas compartilham o objetivo geral de ampliar a escolaridade e a alfabetização de jovens e adultos que nunca frequentaram ou daqueles que abandonaram os sistemas de ensino antes da conclusão das etapas atualmente obrigatórias, isto é, que vivenciaram situações de exclusão escolar. É fato que a concretização desses objetivos se articula também à efetivação de outras metas do PNE, em especial as de universalização da educação básica, mas também as que garantam o financiamento e a formação de professores qualificados para a educação de jovens e adultos, entre outras. Todavia, é importante ressaltar que as Metas 8, 9 e 10 possuem finalidades e contornos específicos que se revelam tanto na particularidade do público para o qual elas se voltam quanto no conjunto das 29 estratégias que devem operacionalizá-las.

A EJA engloba a educação escolar, mas constitui um processo mais amplo do que aquele que se efetiva em instituições oficiais de ensino, incluindo a alfabetização, a ampliação da escolaridade e o desenvolvimento da participação social dos sujeitos na cidadania e no mundo do trabalho. ${ }^{1}$ Para tanto, toma as necessidades e capacidades permanentes de aprendizagem ao longo da vida social como fundamentos para a prática educativa, a partir de diversas finalidades e dos múltiplos contextos nos quais ela pode se processar, como no mundo do trabalho, igrejas, movimentos sociais, associações etc. Como explica Di Pierro (2010), a EJA:

Compreende um conjunto amplo e diverso de processos de formação relacionados ao desenvolvimento da personalidade, à reorientação de valores e comportamentos, à aquisição e ampliação ao longo da vida de conhecimentos básicos, qualificações profissionais ou habilidades socioculturais, visando satisfazer as necessidades de aprendizagem dos indivíduos considerados jovens e adultos pela sociedade a que pertencem. (Di Pierro, 2010).

Na mesma direção, o Marco de Ação de Belém, uma referência para as políticas de EJA - oriundo da VI Conferência Internacional de Educação de Adultos (Confintea VI), realizada no Brasil em 2009 pela Organização das Nações Unidas para a Educação, a Ciência e a Cultura (Unesco) com a participação de 144 países -, deu sequência às conceituações anteriormente consolidadas, como as provenientes da Recomendação de Nairóbi (Unesco, 1976), definindo a EJA como o: "processo de aprendizagem, formal ou informal, em que pessoas consideradas adultas pela sociedade desenvolvem suas capacidades, enriquecem seu conhecimento e aperfeiçoam suas qualificações técnicas e profissionais, ou as redirecionam, para atender suas necessidades e as de sua sociedade" (Confintea, 2010, p. 5).

1 Como registra a Lei de Diretrizes e Bases da Educação (LDB), em seu artigo $1^{\text {o: }}$ "educação abrange os processos formativos que se desenvolvem na vida familiar, na convivência humana, no trabalho, nas instituições de ensino e pesquisa, nos movimentos sociais e organizações da sociedade civil e nas manifestações culturais” (Brasil, 1996). 
O documento aponta que os processos de aprendizagem ocorrem ao longo da vida e não se extinguem quando a pessoa alcança a idade na qual a escolarização não é mais obrigatória por lei. Por isso, esse deve ser o "marco conceitual e um princípio organizador de todas as formas de educação” (Confintea, 2010, p. 6), em especial para aquelas voltadas às populações excluídas dos sistemas escolares, e tem importância na medida em que constitui parte "substantiva do fomento da igualdade de oportunidades” (Valdés et al., 2014, p.78).

A mesma definição também é adotada, de forma mais ampla, na caracterização conceitual empregada pela Unesco na elaboração dos critérios de levantamento de dados no contexto do III Relatório Global sobre Aprendizagem e Educação de Adultos (Grale), documento direcionado ao monitoramento das ações efetivamente levadas a cabo pelos países membros, no que se refere à aprendizagem e educação de adultos em função dos compromissos assumidos pelas nações participantes após a VI Confintea (Unesco, 2016, p. 29).

No contexto brasileiro, tal como já registrara o artigo 37 da Lei de Diretrizes e Bases da Educação Nacional (LDB), Lei nº 9.394 de 1996, a educação escolar de jovens e adultos se destina àqueles que não tiveram acesso ou continuidade de estudos no ensino fundamental e médio na idade considerada própria. Em que pesem as vantagens sociais, econômicas e culturais de que a conclusão da educação básica ocorra idealmente até os 17 anos de idade, ${ }^{2}$ cabe ressaltar novamente que tanto a LDB como a Constituição Federal não extinguem o direito à educação quando a referida idade é superada. Ao contrário, apontam que o poder público mantenha cursos ou exames que habilitem "ao prosseguimento de estudos em caráter regular” (Brasil, 1996, art. 38), que garantam a escolarização de jovens e adultos.

A garantia do acesso à educação formal para jovens e adultos permite o usufruto das produções científicas, culturais e tecnológicas desenvolvidas em sociedade. Além disso, a escolarização se associa à estratificação social, à distribuição de oportunidades ocupacionais e de reconhecimento (Ribeiro, 2007). Ela também tem sido analisada como um fator correlacionado a distintas esferas da vida social: maior escolaridade pode ocasionar uma ampliação da participação democrática (Dahl, 2001, p. 204; Martins Júnior; Dantas, 2004) e o aproveitamento mais significativo da cultura geral e dos bens científicos e tecnológicos existentes nas sociedades modernas (Delors et al., 1996). Torres (2013) destaca que é importante considerar que a educação de jovens e adultos "contribui não apenas para o desenvolvimento econômico ou o emprego, como enfatiza a maioria das políticas governamentais, mas também para o

\footnotetext{
2 A Emenda Constitucional n 59, de 11 de novembro de 2009, estabeleceu a educação básica obrigatória para as pessoas de 4 a 17 anos de idade. De tal modo, ao completar 17 anos, a expectativa é que os sujeitos já tenham integralizado ou estejam em fase de conclusão do ensino médio, etapa que encerra a educação básica.
} 
bem estar dos indivíduos e comunidades, bem como para a promoção da cidadania democrática" (Torres, 2013, p. 2, tradução do autor ${ }^{3}$ ).

Para alguns, a ampliação da escolaridade implica ganhos no plano dos rendimentos salariais e compõe um dos principais determinantes da desigualdade de renda (Barros; Mendonça, 1995). Ribeiro (2011, p. 41) ressalta que a escolarização é "um dos principais meios de acesso a posições ocupacionais e de renda hierarquicamente superiores, logo a diminuição das desigualdades de acesso à educação seria uma das principais maneiras de combater a transmissão de desigualdades ao longo das gerações".

Além de ser um fator associado às mudanças em várias dimensões sociais, a escolarização constitui um direito em si mesmo (Cury, 2008). Esse direito, porém, se distribui de forma desigual na sociedade brasileira e funciona como um critério adicional de estratificação, acesso a oportunidades e exclusões que passam a caracterizar os públicos da EJA, repondo situações de baixa qualificação profissional e cidadã. Mesmo com a obrigatoriedade atualmente em vigor de que as pessoas frequentem a escola entre os 4 e os 17 anos de idade, a conclusão da educação básica continua a ser uma situação menor entre os negros, os residentes no campo e os mais pobres, justamente os sujeitos mais frequentes da EJA. A conclusão do ensino médio, em particular, é um desafio ainda maior (Soares, et al., 2015). Como sintetiza Krawczyk (2011, p. 756), para alguns grupos sociais, integralizar o ensino médio "não faz parte de seu capital cultural, de sua experiência familiar". Desse modo, as trajetórias educacionais dos indivíduos se processam em condições sociais, econômicas e culturais distintas, principalmente em função de sua origem social (Peugny, 2014).

Ao considerar os jovens e adultos com baixa escolaridade, também é preciso ter em conta a pluralidade de identidades e inserções sociais que os caracterizam. Trabalhador, estudante, desempregado, a maternidade e a paternidade, entre outros papéis e condições sociais, passam a descrever "os outros sujeitos", na construção de Arroyo (2012), para os quais a baixa escolaridade adiciona limites objetivos às suas aspirações subjetivas. Como resume Di Pierro (2008, p. 373), a exclusão constitui a identidade que unifica os sujeitos da EJA, pois abarca o conjunto de processos "que permitem explicar a distribuição desigual do analfabetismo e do atraso escolar nas sociedades, incluindo as variáveis de gênero, geração, língua e etnia, considerando ainda a distribuição socioespacial da pobreza nas regiões geográficas, zonas rurais e urbanas e no interior das cidades".

Os sujeitos sem o ensino fundamental ou o médio completo compõem a "demanda potencial" da EJA. No PNE, o conceito aparece de formas distintas: a Meta 9, em sua Estratégia 9.2, optou por denominar o fenômeno de "demanda ativa por vagas na educação de jovens e adultos", enquanto outras metas falam em "demanda manifesta” (Estratégias 1.3 e 4.2) ou “demandas educacionais” (Estratégia 20.1). É preciso

\footnotetext{
3 "contribute not only to economic development or employment, as most government policies emphasize, but also to the welfare of individuals and communities and to the promotion of a democratic citizenship" (Torres, 2013, p. 2).
} 
ponderar que essa abordagem pode implicar uma redução da multidimensionalidade do fenômeno à sua face operacional. A matrícula e a frequência contínua à escola constituem ações sociais de cariz racional, mas também valorativas e afetivas, que exigem possibilidades e "ajustamentos das disposições às situações” (Bourdieu, 2001, p. 190). Assim, mais do que uma decisão exclusivamente racional, é preciso considerar nas análises sobre demanda educacional as desigualdades que marcam as posições dos grupos e que delineiam as decisões possíveis aos indivíduos diante de sua localização na estrutura social.

\begin{abstract}
A propensão das famílias e das crianças para investir na educação depende do grau em que dependem do sistema de ensino para a reprodução de seu patrimônio e de sua posição social, bem como das oportunidades de sucesso prometidas a tais investimentos em função do volume de capital cultural que possuem. Esses dois conjuntos de fatores se sobrepõem a fim de determinar as diferenças consideráveis nas atitudes com relação à escola e ao êxito escolar. (Bourdieu, 2001, p. 264).
\end{abstract}

Para que o sujeito com baixa escolaridade converta uma exclusão formal - não possuir as credenciais escolares - em uma demanda substantiva, isto é, que entenda a conclusão da educação básica como necessidade e direito, é preciso que ele encontre as condições estruturais (escolas, professores, currículos e possibilidade de permanência) para transformar sua situação de "demanda potencial" em uma demanda concreta ou "efetiva", expressa na ação de matricular-se e frequentar com aproveitamento e conclusão os cursos a que eventualmente tiver acesso. É claro que, entre os grupos oriundos de contextos sociais e familiares desprovidos de capital cultural e, consequentemente, de experiência contínua com a escolarização formal, essa transformação pode ser mais complexa e redundar em processos de reprodução da exclusão.

Dito isso, o presente trabalho realiza uma caracterização dos jovens e adultos com baixa escolaridade no Brasil após 2014, ano em que foi publicado o PNE, explora os dados acerca do que é atualmente ofertado na educação de jovens e adultos, bem como o perfil das matrículas e, por fim, analisa as desigualdades nas chances de conclusão do ensino fundamental e do médio com base em um conjunto de características individuais. Com isso, o intento é colaborar com uma compreensão dos desafios associados à concretização das Metas 8, 9 e 10 do PNE mediante o conhecimento de seus públicos.

O texto, além desta introdução, está organizado da seguinte forma: na primeira parte são apresentadas análises descritivas para a caracterização dos jovens e adultos com baixa escolaridade, em específico daqueles sem o ensino fundamental e médio completos, por meio de variáveis como sexo, raça, renda, local de residência e por grupos de idade; na sequência, é realizada uma descrição dos estabelecimentos que ofertam EJA e do número de matrículas existentes; por fim, foram desenvolvidos modelos de regressão logística para entender as desigualdades nas chances de conclusão do ensino fundamental e do médio para diferentes grupos sociais. 


\section{MÉTODOS E BASES DE DADOS}

Os dados utilizados para a realização deste estudo são provenientes da Pesquisa Nacional por Amostra de Domicílios (Pnad), produzida pelo Instituto Brasileiro de Geografia e Estatística (IBGE), relativa aos anos de 2014 e 2015; dos microdados do Censo Escolar da Educação Básica do Instituto Nacional de Estudos e Pesquisas Educacionais Anísio Teixeira (Inep), ${ }^{5}$ coletados nos anos de 2014 a 2016; das Sinopses Estatísticas da Educação Básica de 2014 a 2016; ; e dos Indicadores de Taxa de Transição, que acompanham o fluxo escolar dos estudantes, relativos aos anos de 2014 e 2015, produzidos pelo Inep. ${ }^{7}$

As análises se apoiaram em duas estratégias principais: no uso de estatísticas descritivas e em modelos de regressão logística. O primeiro recurso permitiu que fossem exploradas as características de escolarização e o perfil dos sujeitos com idade igual ou superior a 15 anos que não frequentam a escola e não possuem o ensino fundamental ou médio completo. Essa parte do trabalho foi realizada com o uso da Pnad. Procedeu-se ainda a uma análise exploratória do quantitativo de escolas e matrículas em EJA, com base no Censo Escolar (Inep) e nas Sinopses Estatísticas (Inep). Também foram investigadas as taxas de transição da educação básica nos anos recentes, de modo a compreender a evasão entre os grupos mais jovens, o que foi feito com base nos indicadores de transição elaborados pelo Inep.

Para as análises inferenciais, acerca das desigualdades nas chances de conclusão ou não do ensino fundamental e do médio, foram utilizados modelos de regressão logística binária, desenvolvidos a partir dos dados da Pnad. Tal técnica é útil para a investigação de variáveis dependentes categóricas binárias ou dicotômicas (Hosmer; Lemershow, 2000), permitindo entender a associação e o "impacto relativo da cada variável preditora" (Hair et al., 2009, p. 225) na variável dependente ou a "probabilidade de ocorrência de um evento que se apresenta de forma qualitativa dicotômica, com base no comportamento de variáveis explicativas” (Fávero; Belfiore, 2017, p. 612).

É importante frisar que a Pnad consiste em uma pesquisa domiciliar amostral, com representatividade nacional, regional, por unidades da Federação (UFs) e para algumas regiões metropolitanas. As análises de regressão feitas com base nela precisam incorporar as características do plano amostral complexo, sob pena de o software utilizado considerar os dados como provenientes de uma amostra aleatória simples, o que gera problemas adicionais na estimação do erro amostral. Desse modo, os modelos de regressão elaborados por meio do pacote estatístico SPSS consideraram os dados

\footnotetext{
4 Disponíveis em: http:/www.ibge.gov.br/home/estatistica/populacao/trabalhoerendimento/pnad2015/ microdados.shtm

5 Disponíveis em: http://portal.inep.gov.br/microdados

6 Disponíveis em: http://portal.inep.gov.br/web/guest/sinopses-estatisticas-da-educacao-basica

7 Disponíveis em: http://portal.inep.gov.br/web/guest/indicadores-educacionais
} 
como provenientes de um desenho amostral complexo, o que exigiu o uso de indicação de peso da amostra distinto do peso simples da pessoa (Silva; Pessoa; Lila, 2002). Com tais modelos, foi possível estimar desigualdades nas chances de o indivíduo possuir o ensino fundamental ou o médio completo considerando distintos grupos sociais.

\section{CARACTERIZAÇÃO DOS JOVENS E ADULTOS COM BAIXA ESCOLARIDADE FORA DA ESCOLA (2014-2015)}

A baixa escolaridade de jovens e adultos constitui um fenômeno complexo, associado a desigualdades socioeconômicas, regionais e culturais, mas também a dinâmicas inerentes aos sistemas escolares. Como já registrado (Brasil. Inep, 2016), o número de pessoas que têm acesso ao ensino fundamental é elevado, todavia, a taxa média de evasão ${ }^{8}$ na referida etapa era de 3,6\% no Brasil, no período de 2014/2015, atingindo 2,1\% nos anos iniciais e 5,4\% nos anos finais. Nas escolas com localização rural, a taxa era de $3,1 \%$ para os anos iniciais e $8,5 \%$ para os anos finais, sendo de 14,7\% (Gráfico 1) no $9^{\circ}$ ano (Brasil. Inep, 2017). Por isso, ao pensar o direito à educação, é importante que sejam consideradas não apenas as taxas de ingresso na escola, mas também os sujeitos que não integralizam os níveis obrigatórios em função dos processos de exclusão ao longo da educação básica (Simões, 2016).

No ensino médio, as taxas de evasão também são consideráveis, sendo mais elevadas na $1^{\mathrm{a}}$ e na $2^{\mathrm{a}}$ série, principalmente nas escolas com localização rural, em que atinge valor superior a $14 \%$ no $1^{\circ}$ ano (Gráfico 2). Já as taxas de migração para a EJA no ensino médio, em 2014/2015, eram de 2,0\%. Assim, em um contexto de "universalização" do acesso inicial, a evasão escolar continua a ser um dos principais fenômenos responsáveis pela baixa escolaridade de jovens e adultos.

Os processos que se associam à evasão são complexos. Para alguns analistas, o fenômeno se vincula à escolha racional de pais de enviarem os filhos para a escola ao invés de os direcionarem para o mercado de trabalho (Neri, 2009), o que tende a ser mais provável quando o pai detém as informações acerca das vantagens em médio prazo do investimento em educação, mas que não se coloca em patamares idênticos para os mais pobres, que não podem protelar o ingresso no mundo do trabalho. Assim, as necessidades de conciliação entre trabalho e educação também estariam associadas a níveis elevados de evasão, sobretudo entre os mais jovens, quando as transições educação/trabalho se agudizam (Rocha, 2008) e ganham maior intensidade, especialmente entre os sujeitos pertencentes aos segmentos mais pobres, para os quais as exigências de obter rendimentos por meio do trabalho se tornam mais intensas (Machado; Rodrigues, 2013). Outras análises destacam componentes

\footnotetext{
8 Ver nota técnica: http://download.inep.gov.br/informacoes_estatisticas/indicadores_educacionais/2007_2016/ nota_tecnica_taxas_transicao_2007_2016.pdf
} 
internos às dinâmicas escolares, como as taxas de repetência, como importantes para compreender a evasão (Ribeiro, 1991).

Lima (2016, p. 17-18), refletindo sobre as relações da exclusão com a EJA, destaca que os sistemas escolares continuam

\begin{abstract}
a reproduzir desigualdades sociais de todo tipo, a 'fabricar' insucesso e abandono, a remeter os alunos para fora dela a fim de que, paradoxalmente, o sistema lhes oferecesse (posteriormente) um novo processo de escolarização, frequentemente conduzido na mesma escola e conforme as mesmas regras de sua gramática tradicional. Tais justificativas reafirmam a dialética de fatores extra e intraescolares na explicação de fenômenos educacionais em geral e da educação de jovens e adultos em particular (Silva; Bonamino; Ribeiro, 2012).
\end{abstract}

É importante ressaltar, pela análise dos Gráficos 1 e 2, a permanência de situações nas quais o indivíduo teve acesso ao sistema escolar, mas saiu dele antes de integralizar as etapas obrigatórias. Desse modo, um contingente significativo dos que não possuem a educação básica completa no presente já frequentaram alguma etapa escolar no passado. A evasão se concentra, sobretudo, na transição para o último ano do ensino fundamental e nos anos iniciais do ensino médio, em faixas etárias de transição para a adolescência e a juventude. Logo, isso implica a reprodução da baixa escolaridade para grupos mais jovens.

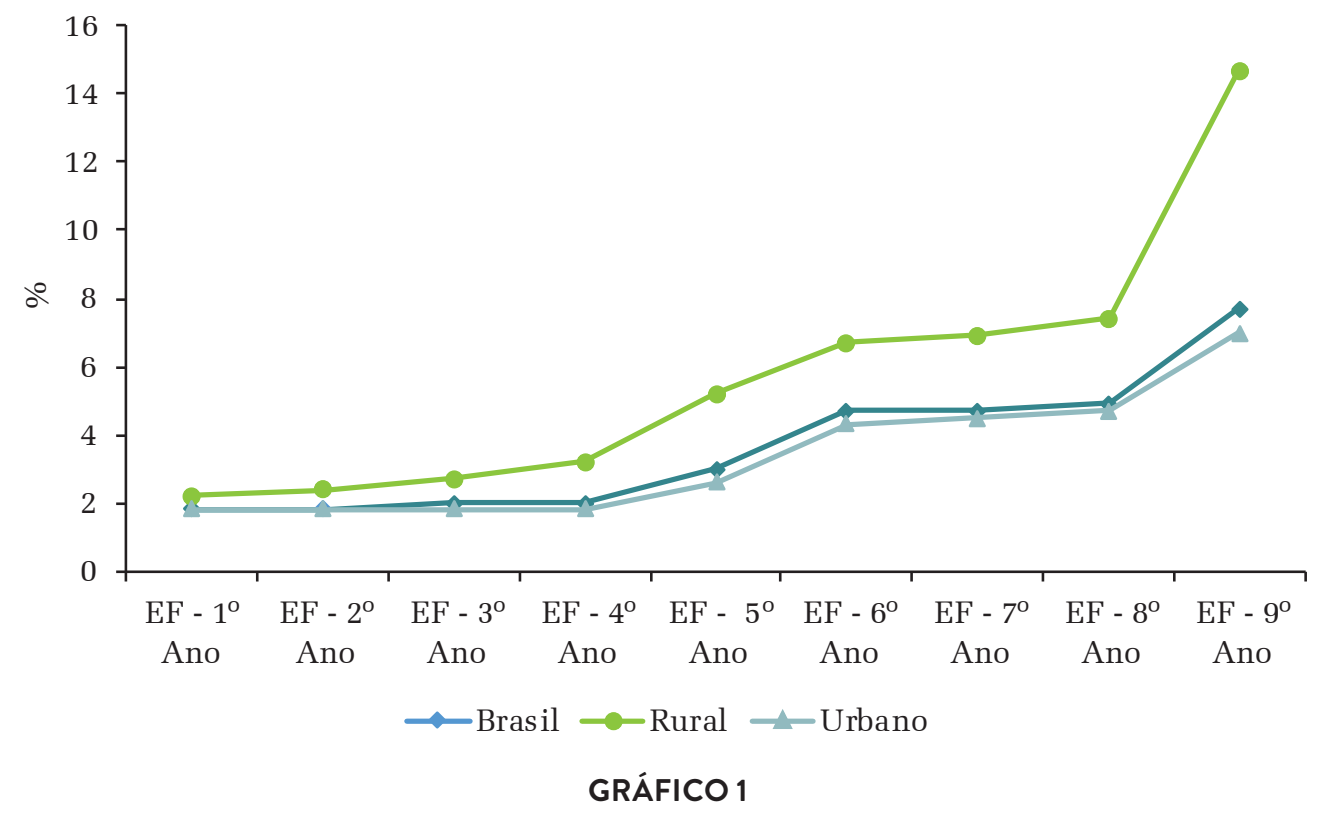

TAXA DE EVASÃO NO ENSINO FUNDAMENTAL, POR BRASIL E LOCALIZAÇÃO - 2014-2015

Fonte: Elaboração própria com base em Indicadores Educacionais Inep/Deed (Taxas de transição). 


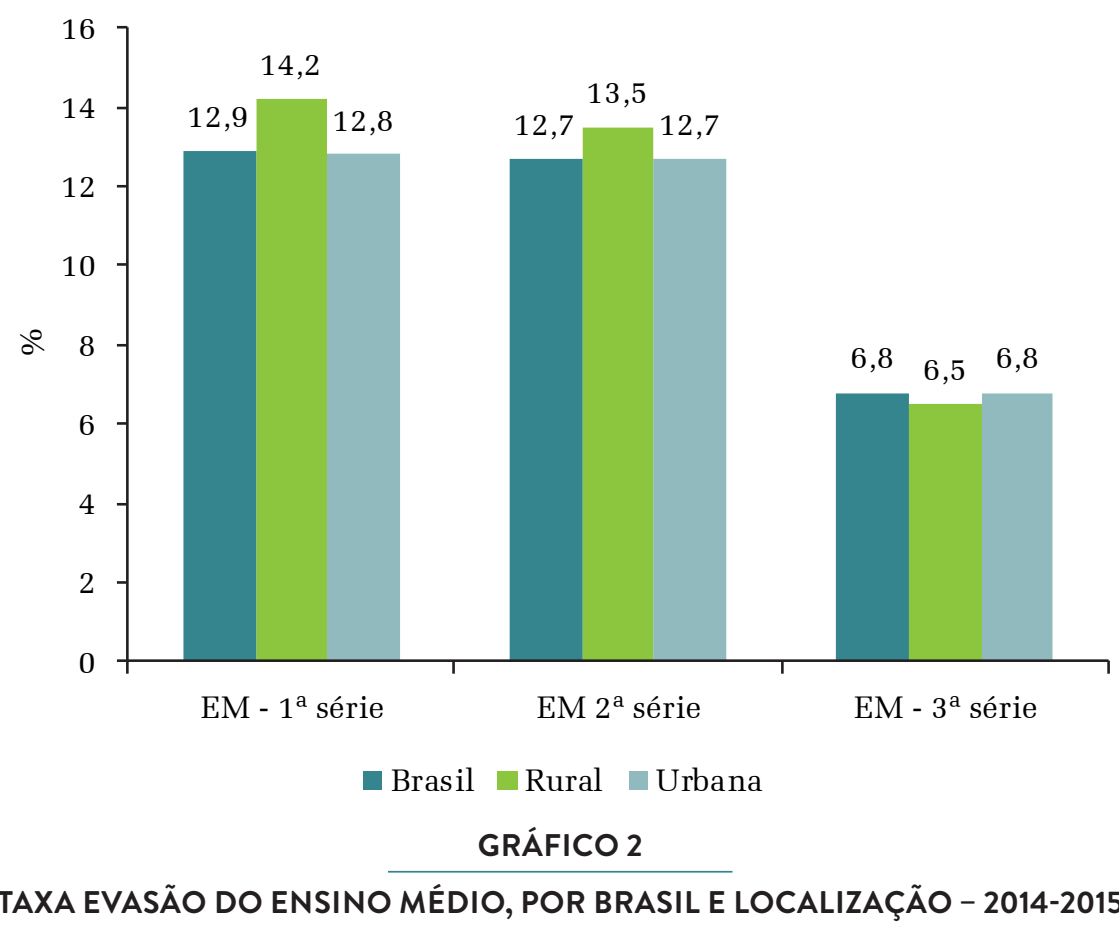

Fonte: Elaboração própria com base em Indicadores Educacionais Inep/Deed (Taxas de transição).

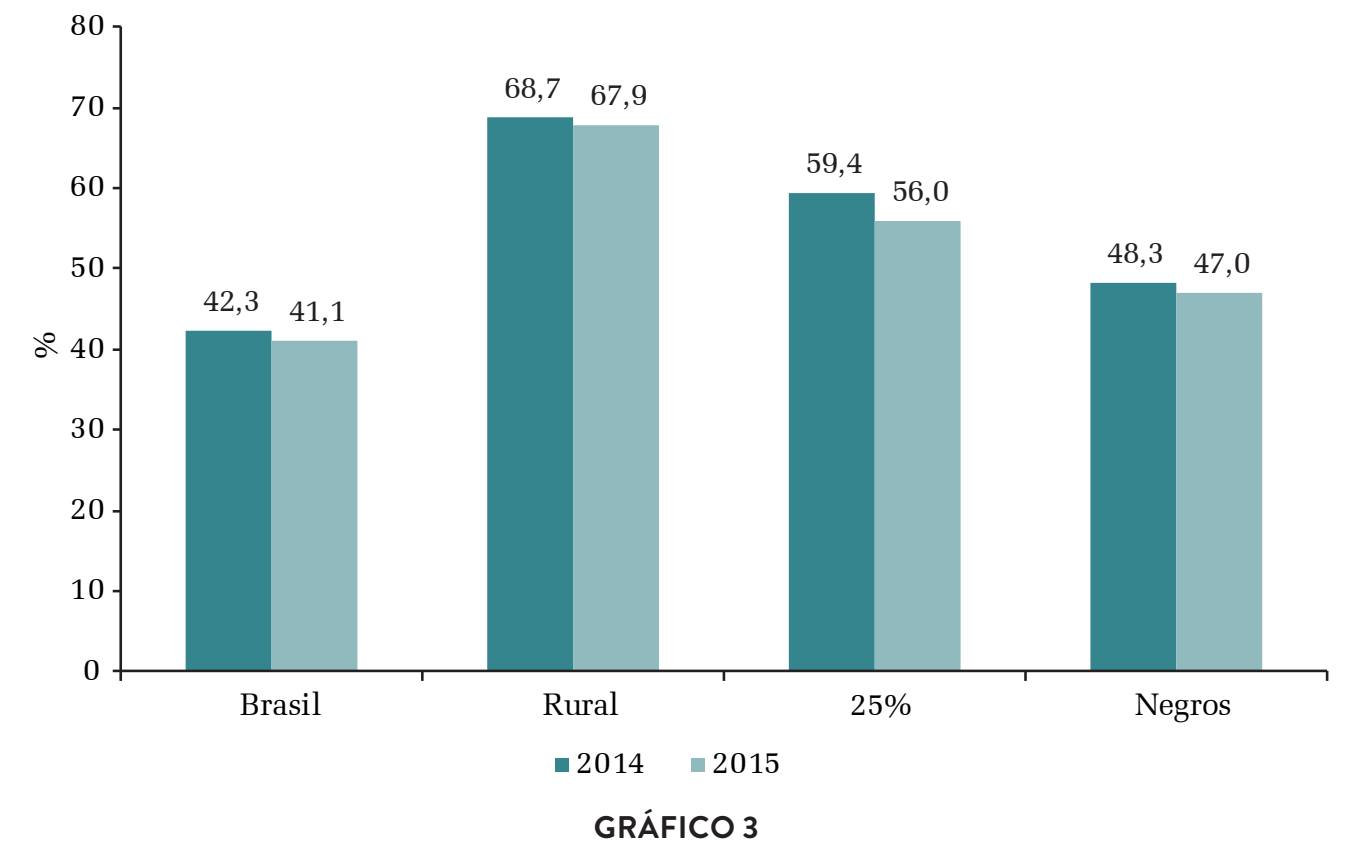

PERCENTUAL DA POPULAÇÃO COM 15 ANOS OU MAIS DE IDADE QUE NÃO FREQUENTA A ESCOLA E NÃO POSSUI ENSINO FUNDAMENTAL COMPLETO, POR BRASIL, LOCALIZAÇÃO E 25\% MAIS POBRES - 2014-2015

Fonte: Elaboração própria com base em dados da Pnad/IBGE (2014/2015). 
A análise das características dos sujeitos que estavam fora da escola sem a conclusão da educação básica adiciona componentes para a compreensão do que seria uma demanda por EJA. O percentual da população com mais de 15 anos de idade que não frequentava a escola e não possuía sequer o ensino fundamental era consideravelmente alto. Nas áreas rurais, em 2015, 67,9\% da população com 15 ou mais anos de idade que não estava na escola não possuía o ensino fundamental completo (Gráfico 3). Entre os 25\% mais pobres, sob os mesmos critérios, em 2015, 56,0\% não tinham o ensino fundamental.

Ao observar a idade dos que estão fora da escola e não possuem o ensino fundamental completo (Gráfico 4), nota-se que, após os 18 anos, o percentual cresce à medida que se ampliam as faixas etárias (Correlação de Pearson de 0,98, em 2015). Nesse caso, em particular, a correlação ideal seria negativa, isto é, à medida que se ampliariam as faixas etárias diminuiriam os percentuais daqueles que não possuem o ensino fundamental. O cenário contemporâneo ocorre em função das situações pregressas quando as coortes mais velhas não obtiveram acesso à escolarização, e isso tenderia a diminuir com a universalização do direito à educação para gerações mais novas. Todavia, a análise dos grupos mais jovens demonstra que é grande também o percentual de pessoas sem o ensino fundamental completo que possuem menos de 30 anos de idade (Gráfico 4).



PERCENTUAL DA POPULAÇÃO COM 16 ANOS OU MAIS QUE NÃO FREQUENTA A ESCOLA E NÃO POSSUI O ENSINO FUNDAMENTAL COMPLETO, POR BRASIL, LOCALIZAÇÃO E 25\% MAIS POBRES - 2015

Fonte: Elaboração própria com base em dados da Pnad/IBGE (2015) 
Entre os residentes no campo e os oriundos dos 25\% mais pobres da população, ao observar especificamente as pessoas com idade entre de 21 e 30 anos e que estavam fora da escola, percebe-se que o percentual dos que não possuíam sequer o ensino fundamental superava $30 \%$ e, nos grupos entre 30 e 40 anos, era superior a 40\% (Gráfico 4). Assim, em que pese a significativa ampliação do acesso à educação básica nos anos recentes (Brasil, 2016), o perfil dos indivíduos sem o ensino fundamental completo não se restringe aos grupos de maior idade, mas continua a incidir entre as gerações mais novas.

A análise dos dados por grandes regiões revela que o Nordeste apresentava o maior percentual de pessoas fora da escola e que não possuíam o ensino fundamental completo, 52,6\% em 2014 e 51,7\% em 2015 (Tabela 1). É bom destacar, porém, que, apesar de possuir o menor percentual relativo de pessoas sem o ensino fundamental, a região Sudeste, por ser a mais populosa do País, abrigava o maior quantitativo de indivíduos com idade superior a 15 anos que não tinham o ensino fundamental completo, mais de 21 milhões em 2014 e 2015 (Tabela 1). No Nordeste, o quantitativo dos que não frequentavam a escola e estavam sem o ensino fundamental era superior a 19 milhões de pessoas (Tabela 1).

De modo geral, as comparações entre os anos de 2014 e 2015, por um lado, apontam uma tendência de redução no quantitativo dos que não possuem o ensino fundamental completo, o que pode denotar a ampliação do acesso e a melhoria nos fluxos escolares; por outro lado, o contingente dos que não possuem o ensino fundamental ainda permanece elevado em todas elas (Tabela 1).

TABELA 1

PERCENTUAL E TOTAL DA POPULAÇÃO COM 15 ANOS OU MAIS DE IDADE QUE NÃO FREQUENTA A ESCOLA, SEGUNDO A CONCLUSÃO DO ENSINO FUNDAMENTAL, POR BRASIL E GRANDES REGIÕES - 2014/2015

(continua)

\begin{tabular}{|c|c|c|c|c|c|}
\hline \multirow{2}{*}{ Região } & \multirow{2}{*}{$\begin{array}{l}\text { Concluiu o ensino } \\
\text { fundamental }\end{array}$} & \multicolumn{2}{|c|}{2014} & \multicolumn{2}{|l|}{2015} \\
\hline & & Total & $\%$ & Total & $\%$ \\
\hline \multirow{3}{*}{ Brasil } & Não & 58.561 .207 & 42,3 & 57.928 .684 & 41,1 \\
\hline & Sim & 79.954 .043 & 57,7 & 83.175 .902 & 58,9 \\
\hline & Total & 138.515 .250 & 100 & 141.104 .586 & 100 \\
\hline \multirow{3}{*}{ Norte } & Não & 4.815 .210 & 46,2 & 4.859 .976 & 45,2 \\
\hline & Sim & 5.601 .776 & 53,8 & 5.882 .901 & 54,8 \\
\hline & Total & 10.416 .986 & 100 & 10.742 .877 & 100 \\
\hline \multirow{3}{*}{ Nordeste } & Não & 19.359 .275 & 52,6 & 19.387.760 & 51,7 \\
\hline & Sim & 17.438 .757 & 47,4 & 18.108 .060 & 48,3 \\
\hline & Total & 36.798.032 & 100 & 37.495 .820 & 100 \\
\hline
\end{tabular}


TABELA 1

\section{PERCENTUAL E TOTAL DA POPULAÇÃO COM 15 ANOS OU MAIS DE IDADE QUE NÃO FREQUENTA A ESCOLA, SEGUNDO A CONCLUSÃO DO ENSINO FUNDAMENTAL, POR BRASIL E GRANDES REGIÕES - 2014/2015}

\begin{tabular}{|c|c|c|c|c|c|}
\hline \multirow{2}{*}{ Região } & \multirow{2}{*}{$\begin{array}{l}\text { Concluiu o ensino } \\
\text { fundamental }\end{array}$} & \multicolumn{2}{|c|}{2014} & \multicolumn{2}{|l|}{2015} \\
\hline & & Total & $\%$ & Total & $\%$ \\
\hline \multirow{3}{*}{ Sudeste } & Não & 21.837 .975 & 36,1 & 21.431 .445 & 34,8 \\
\hline & Sim & 38.619 .779 & 63,9 & 40.065 .989 & 65,2 \\
\hline & Total & 60.457 .754 & 100 & 61.497 .434 & 100 \\
\hline \multirow{3}{*}{ Sul } & Não & 8.428 .759 & 40,9 & 8.327 .098 & 39,7 \\
\hline & Sim & 12.187 .138 & 59,1 & 12.640 .117 & 60,3 \\
\hline & Total & 20615.897 & 100 & 20.967 .215 & 100 \\
\hline \multirow{3}{*}{ Centro-Oeste } & Não & 4.119 .988 & 40,3 & 3.922 .405 & 37,7 \\
\hline & Sim & 6.106 .593 & 59,7 & 6.478 .835 & 62,3 \\
\hline & Total & 10.226.581 & 100 & 10.401 .240 & 100 \\
\hline
\end{tabular}

Fonte: Elaboração própria com base em dados da Pnad/IBGE (2014/2015).

Como exposto, os dados indicam que a demanda potencial por educação de jovens e adultos na atualidade não pode ser tratada exclusivamente como resultado da situação escolar de coortes mais velhas, que seriam provenientes de contextos nos quais o ensino fundamental ainda não era universalizado, situação que tenderia a desaparecer em função da variável tempo, uma vez que entre as coortes mais novas o ingresso e a conclusão do ensino fundamental estariam universalizados. Os sistemas de ensino continuam a produzir uma demanda para as políticas de EJA. Os dados de 2014 e 2015 apontam que, mesmo entre os jovens que já tiveram acesso à escola, um contingente elevado continua deixando-a sem concluir o ensino fundamental (Gráfico 5), o que implica desafios e problemáticas específicas, por se tratar de um grupo que, em geral, possui experiência recente com a instituição escolar.

É fato que entre as coortes mais velhas o percentual dos que frequentaram a escola e a deixaram sem concluir o ensino fundamental é superior ao que se visualiza nos grupos mais jovens, o que indica uma melhoria na eficiência dos sistemas escolares nos anos recentes. Porém, um olhar sobre as faixas de 18 a 29 anos de idade mostra que o percentual dos que deixaram de frequentar a escola e não possuem o ensino fundamental é próximo de $20 \%$. Já dentre o grupo que não mais frequenta a escola, o percentual sem o ensino fundamental completo - considerando os indivíduos com idade de 15 anos, por exemplo - era superior a 75\% em todos os grupos (Gráfico 5).

A população do campo apresenta o percentual mais elevado de indivíduos que frequentaram antes a escola e a deixaram sem o ensino fundamental completo, pois, 
excetuando o grupo com 20 anos de idade, em todos os casos o percentual era superior a $30 \%$. A situação é parecida com o grupo dos $25 \%$ mais pobres, para os quais o percentual chega próximo a $40 \%$ ao considerarmos aqueles acima de 30 anos, assim como para os negros (Gráfico 5).

\begin{tabular}{|c|c|c|c|c|}
\hline Idade & Brasil (\%) & Rural (\%) & $25 \%$ mais pobres (\%) & Negros (\%) \\
\hline 15 & 75,9 & 79,7 & 82,5 & 77,7 \\
\hline 16 & 59,0 & 58,4 & 65,7 & 66,0 \\
\hline 17 & 34,5 & 47,3 & 48,4 & 39,4 \\
\hline 18 & 22,4 & 34,7 & 34,7 & 27,5 \\
\hline 19 & 19,3 & 31,5 & 31,3 & 21,9 \\
\hline 20 & 17,9 & 26,5 & 28,4 & 21,3 \\
\hline 21 & 17,7 & 31,5 & 31,0 & 20,0 \\
\hline 22 & 18,3 & 36,3 & 33,6 & 22,3 \\
\hline 23 & 18,3 & 33,6 & 34,6 & 21,9 \\
\hline 24 & 17,4 & 34,2 & 32,9 & 21,9 \\
\hline 25 & 17,7 & 33,8 & 36,0 & 22,4 \\
\hline 26 & 18,5 & 39,9 & 39,0 & 23,3 \\
\hline 27 & 18,0 & 42,0 & 36,2 & 23,8 \\
\hline 28 & 18,7 & 42,4 & 39,2 & 23,7 \\
\hline 29 & 19,6 & 47,7 & 40,9 & 25,2 \\
\hline 30 & 20,1 & 47,6 & 42,1 & 25,7 \\
\hline 31 & 20,0 & 44,4 & 39,3 & 25,8 \\
\hline 32 & 22,3 & 49,8 & 44,5 & 27,9 \\
\hline 33 & 22,9 & 46,6 & 48,0 & 29,6 \\
\hline 34 & 24,1 & 55,4 & 47,7 & 31,0 \\
\hline 35 & 26,1 & 59,7 & 49,3 & 32,4 \\
\hline 36 & 29,0 & 61,9 & 54,0 & 34,7 \\
\hline 37 & 31,4 & 65,8 & 57,0 & 38,1 \\
\hline 38 & 33,6 & 68,1 & 59,6 & 42,5 \\
\hline 39 & 34,5 & 67,6 & 59,4 & 41,4 \\
\hline 40 & 35,9 & 70,5 & 61,0 & 44,2 \\
\hline 41 & 35,9 & 70,9 & 62,6 & 42,5 \\
\hline 42 & 38,6 & 72,3 & 62,2 & 45,1 \\
\hline 43 & 33,9 & 64,3 & 57,1 & 41,7 \\
\hline 44 & 33,1 & 60,7 & 56,8 & 40,6 \\
\hline 45 & 34,4 & 64,1 & 57,6 & 41,6 \\
\hline 46 & 35,0 & 62,6 & 57,0 & 41,2 \\
\hline 47 & 33,7 & 60,0 & 57,1 & 41,2 \\
\hline 48 & 38,4 & 67,3 & 67,2 & 46,6 \\
\hline 49 & 39,4 & 72,9 & 66,3 & 47,7 \\
\hline 50 & 37,2 & 69,2 & 68,1 & 45,1 \\
\hline
\end{tabular}

GRÁFICO 5

\section{PERCENTUAL DA POPULAÇÃO DE 15 A 50 ANOS DE IDADE QUE NÃO FREQUENTA A ESCOLA, FREQUENTOU ANTERIORMENTE E NÃO POSSUI O ENSINO FUNDAMENTAL COMPLETO, POR BRASIL, LOCALIZAÇÃO RURAL, 25\% MAIS POBRES E COR/RAÇA - 2015}

Fonte: Elaboração própria com base em dados da Pnad/IBGE (2015).

A transição entre escola e trabalho é comumente associada à evasão escolar, ao passo que os esforços para conciliar atividades laborais com o retorno aos estudos representam um componente importante do perfil dos sujeitos da EJA. Do ponto de 
vista da ocupação, uma análise da inserção profissional dos sujeitos sem o ensino fundamental completo revela uma concentração em trabalhos comumente marcados por graus maiores de informalidade, menores rendimentos e ausência de proteção social. Isso fica patente ao se observar o percentual dos que estão ocupados em atividades voltadas para o próprio consumo ou uso que não possuem o ensino fundamental completo. De modo inverso, ocupações tradicionalmente caracterizadas por maiores níveis de formalização e rendimentos reúnem um contingente menor de sujeitos sem o ensino fundamental completo (Gráfico 6).

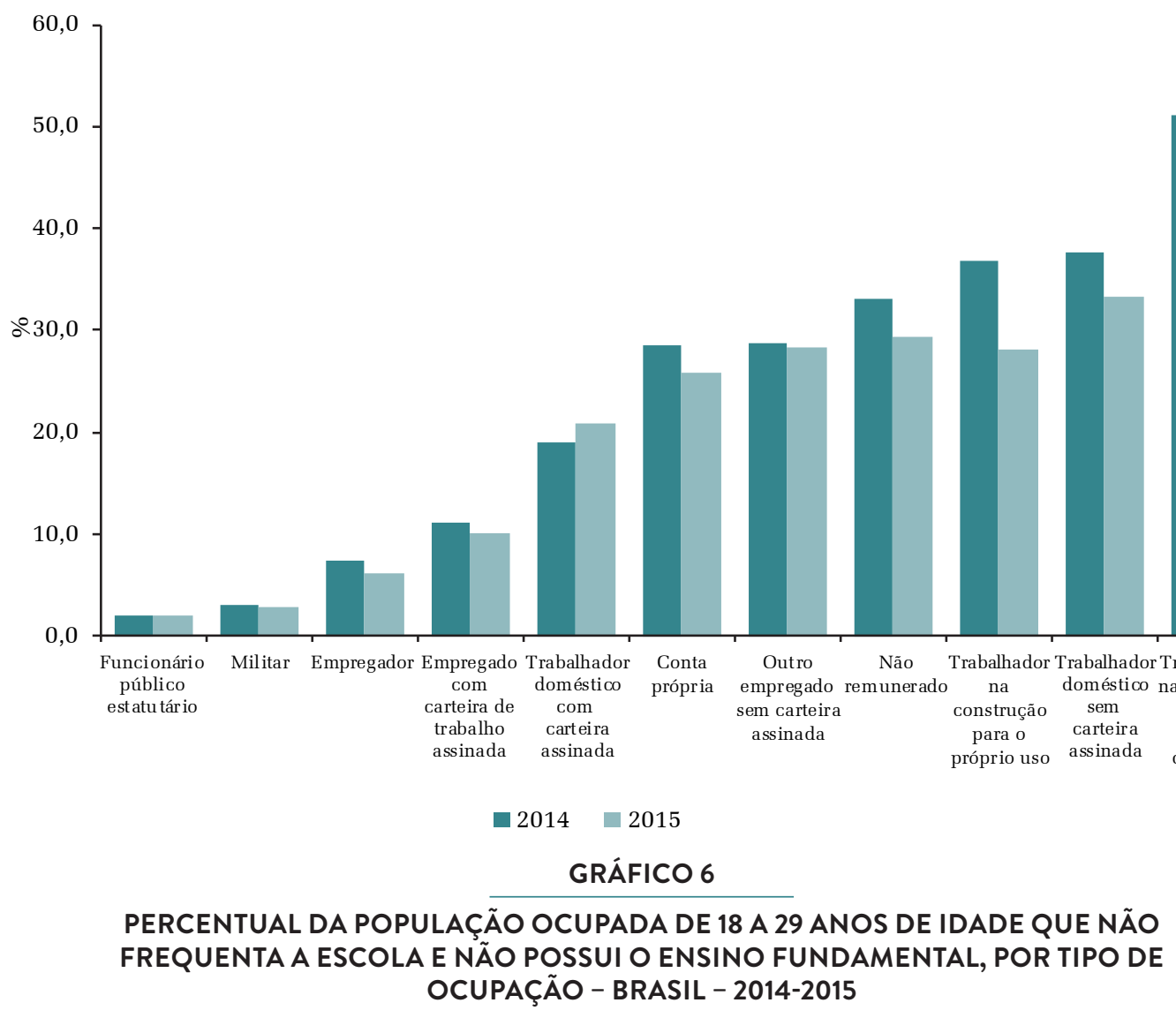

Fonte: Elaboração própria com base em dados da Pnad/IBGE (2014/2015).

Ainda sobre os indivíduos ocupados, cabe ressaltar que a inserção precoce no mundo do trabalho, especialmente na infância, apresenta associação com a baixa escolaridade (Santos, 2017). Entre os indivíduos ocupados, com idade entre 18 e 29 anos, daqueles que começaram a trabalhar antes dos 9 anos, 64,5\% em 2015 (62,3\% em 2014) tinham o ensino fundamental completo; já entre os que começaram a trabalhar entre 20 e 24 anos, o percentual dos que tinham o fundamental completo era de 93,1\% em 2015. Em outras palavras, à medida que se amplia a idade em que ocorreu o ingresso no mercado de trabalho, reduzem-se os percentuais dos que não têm o ensino fundamental completo (Gráfico 7). 


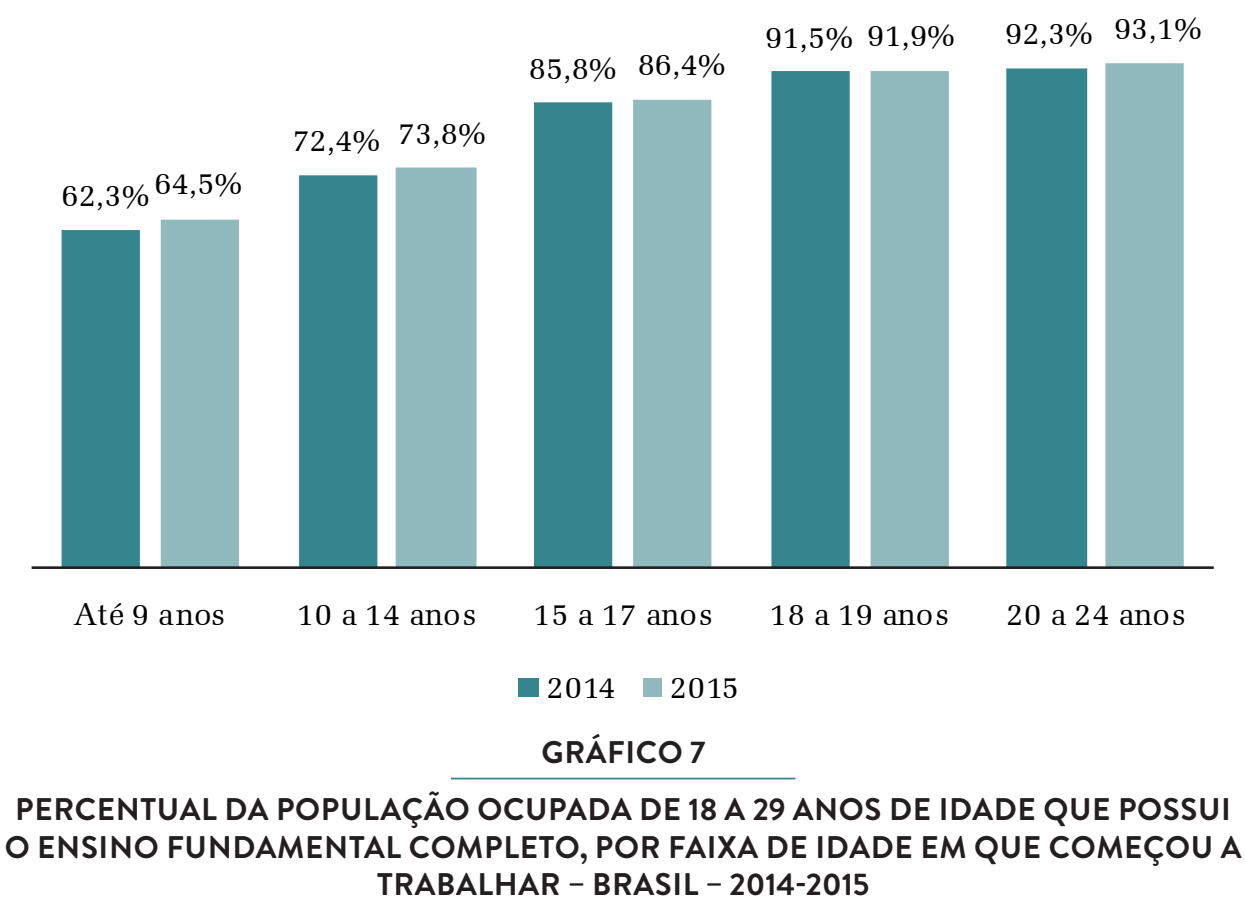

Fonte: Elaboração própria com base em dados da Pnad/IBGE (2014/2015).



PERCENTUAL DA POPULAÇÃO COM 19 ANOS OU MAIS QUE NÃO FREQUENTA A ESCOLA E NÃO CONCLUIU O ENSINO MÉDIO - BRASIL - 2014-2015

Fonte: Elaboração própria com base em dados da Pnad/IBGE (2014/2015). 
Paralelamente, o foco na integração entre políticas de EJA e educação profissional precisa considerar que as trajetórias de exclusão escolar se encadeiam às inserções precárias no mundo do trabalho (Gráfico 6) e desembocam em desafios particulares à definição das formações e dos perfis profissionais almejados pelos cursos.

Até aqui, foram considerados os dados de conclusão do ensino fundamental de diversos grupos etários e algumas desagregações. Na sequência, a análise da conclusão do ensino médio apresenta cenários ainda mais complexos. Entre 2014 e 2015, o percentual daqueles com mais de 19 anos de idade que não frequentavam mais a escola e não tinham o ensino médio completo era superior a 50\% no Brasil; acima de $80 \%$ para as populações do campo e de $70 \%$ para os pertencentes aos $25 \%$ mais pobres. Esse conjunto engloba toda a população com mais de 19 anos (Gráfico 8).

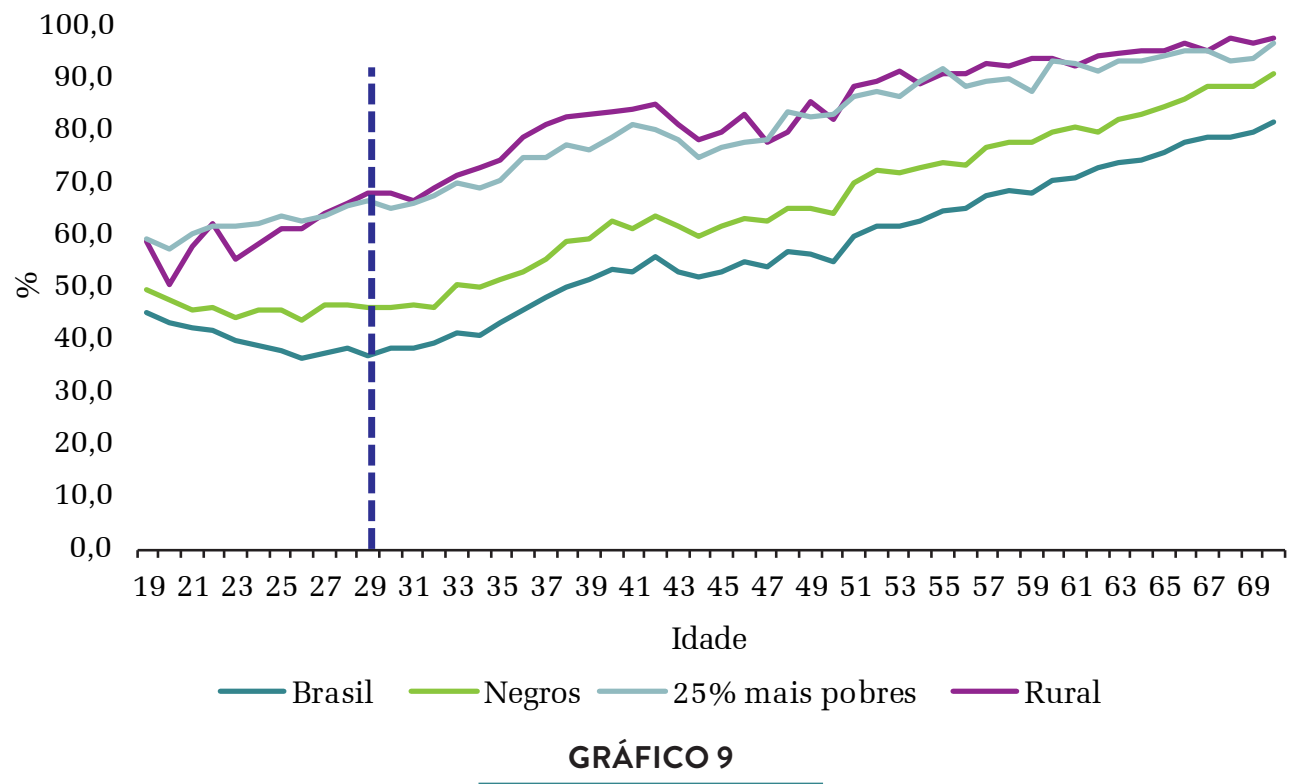

PERCENTUAL DA POPULAÇÃO COM 19 ANOS OU MAIS QUE NÃO FREQUENTA A ESCOLA E NÃO POSSUI O ENSINO MÉDIO COMPLETO, POR IDADE E DESAGREGAÇÕES - BRASIL $-2015$

Fonte: Elaboração própria com base em dados da Pnad/IBGE (2015).

Ao analisar como a taxa de conclusão do ensino médio se distribui entre os grupos etários, nas populações do campo e entre os $25 \%$ mais pobres, na faixa de 19 a 29 anos, mais de 50\% dos que não frequentavam a escola não havia concluído o ensino médio; já para o grupo com 40 anos, mais de 80\% não o concluíram (Gráfico 9). Desse modo, para todos os subgrupos investigados, o percentual daqueles sem a educação básica completa era elevado mesmo entre os mais novos. A baixa escolaridade entre grupos mais jovens, com evidentes diferenças, persiste tanto no caso da conclusão do ensino fundamental quanto no da integralização da educação básica. Em adição, a análise sobre os níveis mais elevados obtidos pelos grupos demonstra que o percentual dos que atingiram o ensino superior é muito reduzido, sobretudo entre os $25 \%$ mais pobres e os residentes 
no campo. Em nível nacional, 10,3\% dos jovens de 18 a 29 anos que não frequentavam a escola possuíam o ensino superior completo, entre os residentes no campo apenas 2,3\% e para os mais pobres somente 1,1\%. Para esses grupos, era alto o percentual dos que tinham, no máximo, o ensino médio incompleto (Gráfico 10). As trajetórias escolares, portanto, continuam aparentemente a ser dependentes das origens sociais e da posição que os indivíduos ocupam, e isso é uma carcaterística relavante para a compreensão dos sujeitos que se convertem em "demanda potencial” da educação de jovens e adultos.



Fonte: Elaboração própria com base em dados da Pnad/IBGE (2015).

Dando sequência à caracterização dos sujeitos com baixa escolaridade, a observação das informações sobre analfabetismo absoluto confirma que o fenômeno se concentra nas coortes mais velhas. No entanto, ao consideramos os quatro grupos principais abordados neste texto, percebe-se também que o percentual dos que não sabem ler e escrever se amplia à medida que aumentam as idades. Os dados indicam, considerando as variações amostrais, que após os 18 anos e, mais acentuadamente, após os 30, o percentual aumenta com mais ênfase em todos os segmentos. Entre os que vivem no campo e entre os $25 \%$ mais pobres, a curva sofre uma mudança mais acentuada após os 32 anos (Gráfico 11). 


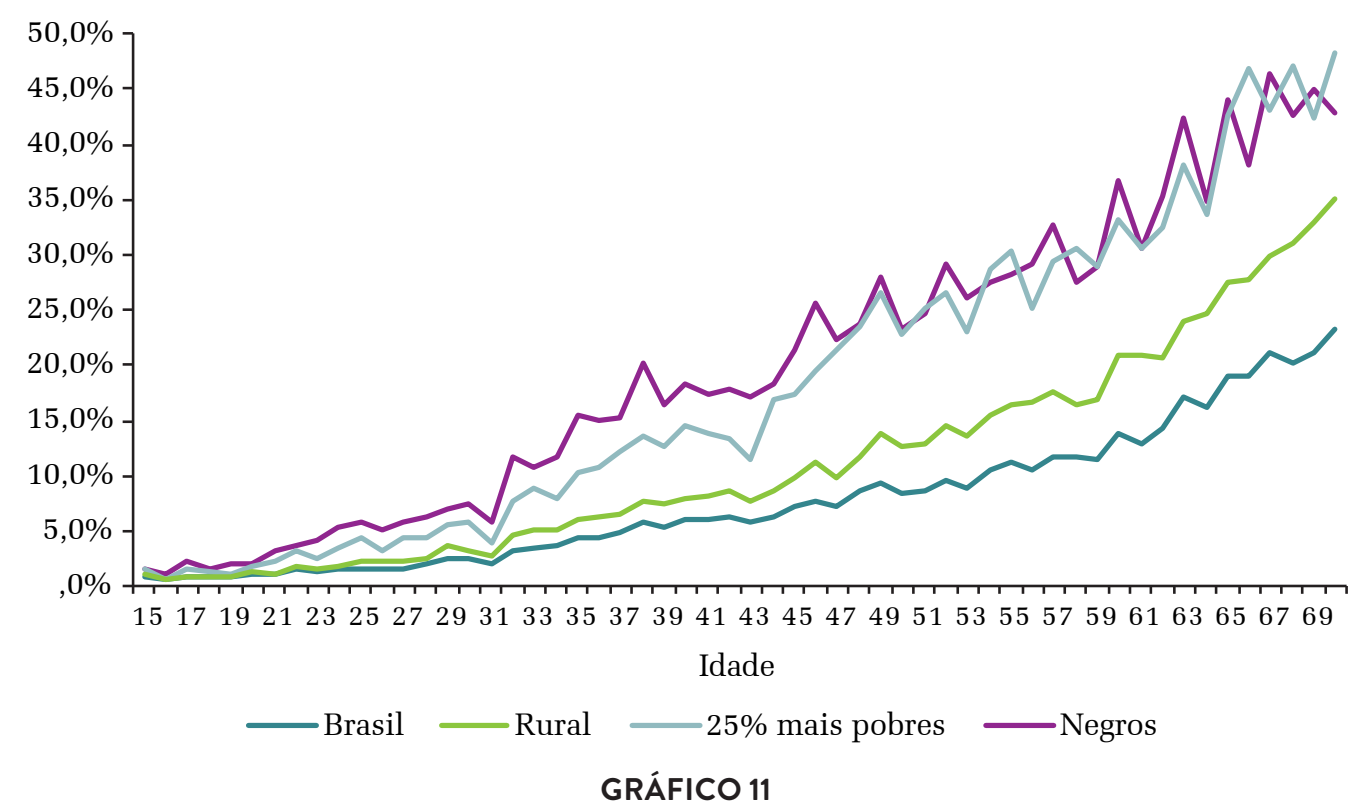

PERCENTUAL DA POPULAÇÃO ENTRE 15 E 70 ANOS QUE NÃO SABE LER OU ESCREVER, POR BRASIL, LOCALIZAÇÃO RURAL, 25\% MAIS POBRES E COR/RAÇA - 2015

Fonte: Elaboração própria com base em dados da Pnad/IBGE (2015).

\section{A OFERTA DE EDUCAÇÃO DE JOVENS E ADULTOS NO BRASIL (2014-2016)}

As análises anteriores permitiram delinear os percentuais e o perfil geral dos sujeitos que não frequentam a escola e não possuem o ensino fundamental ou o médio completo, bem como a distribuição das taxas de analfabetismo. De modo adicional, cabe um breve estudo do que tem sido ofertado na educação de jovens e adultos quanto às escolas, ao quantitativo e à distribuição das matrículas nos anos recentes.

Em 2014, 18,82\% dos estabelecimentos de ensino básico no País ofereciam educação de jovens e adultos, já em 2016 o percentual era de 17,18\% (Gráfico 12). A quantidade de escolas que ofertavam EJA caiu, no mesmo período, de 35.516 para 31.964, redução de 3.552 estabelecimentos (Gráfico 12). A maior queda ocorreu entre as instituições com localização rural, com 3.252 estabelecimentos deixando de oferecer EJA no período, o que implicou uma redução de 23\% no total de instituições escolares que ofertavam EJA (Gráfico 12). ${ }^{9}$

\footnotetext{
9 A redução no número de estabelecimentos e de matrículas da EJA pode se associar a uma melhoria nas taxas de transição na educação básica, de modo que um percentual maior de pessoas permanece e integraliza a educação básica em idades ideais. É preciso considerar também a efetiva redução das oportunidades de retorno aos estudos para os que deixaram a escola. Ambas as hipóteses integram objetivos posteriores deste trabalho. Cabe investigar também o papel que os fatores de ponderação trazidos pela Lei n ${ }^{\circ}$ 11.494, de 2007, que regulamenta o Fundo de Manutenção e Desenvolvimento da Educação Básica e de Valorização dos Profissionais da Educação (Fundeb), efetivamente exercem sobre a oferta de vagas.
} 
Ainda sobre o campo, em 2014, 20\% dos estabelecimentos de ensino ofereciam EJA, percentual que foi para 17,51\% em 2017. Em relação a esse último dado, é importante ressaltar que é justamente nas áreas rurais que se verificaram os percentuais mais elevados de pessoas fora da escola sem o ensino fundamental ou a educação básica completa (Gráficos 3, 4 e 5), o que traz desafios adicionais à ampliação da escolaridade do grupo. Ao consideramos que a conciliação entre trabalho e escolarização é mais frequente entre os residentes nas áreas rurais, a ausência de instituições que ofereçam possibilidades de escolarização pode acarretar dificuldades ainda maiores para o processo de reinserção escolar e continuação dos estudos.

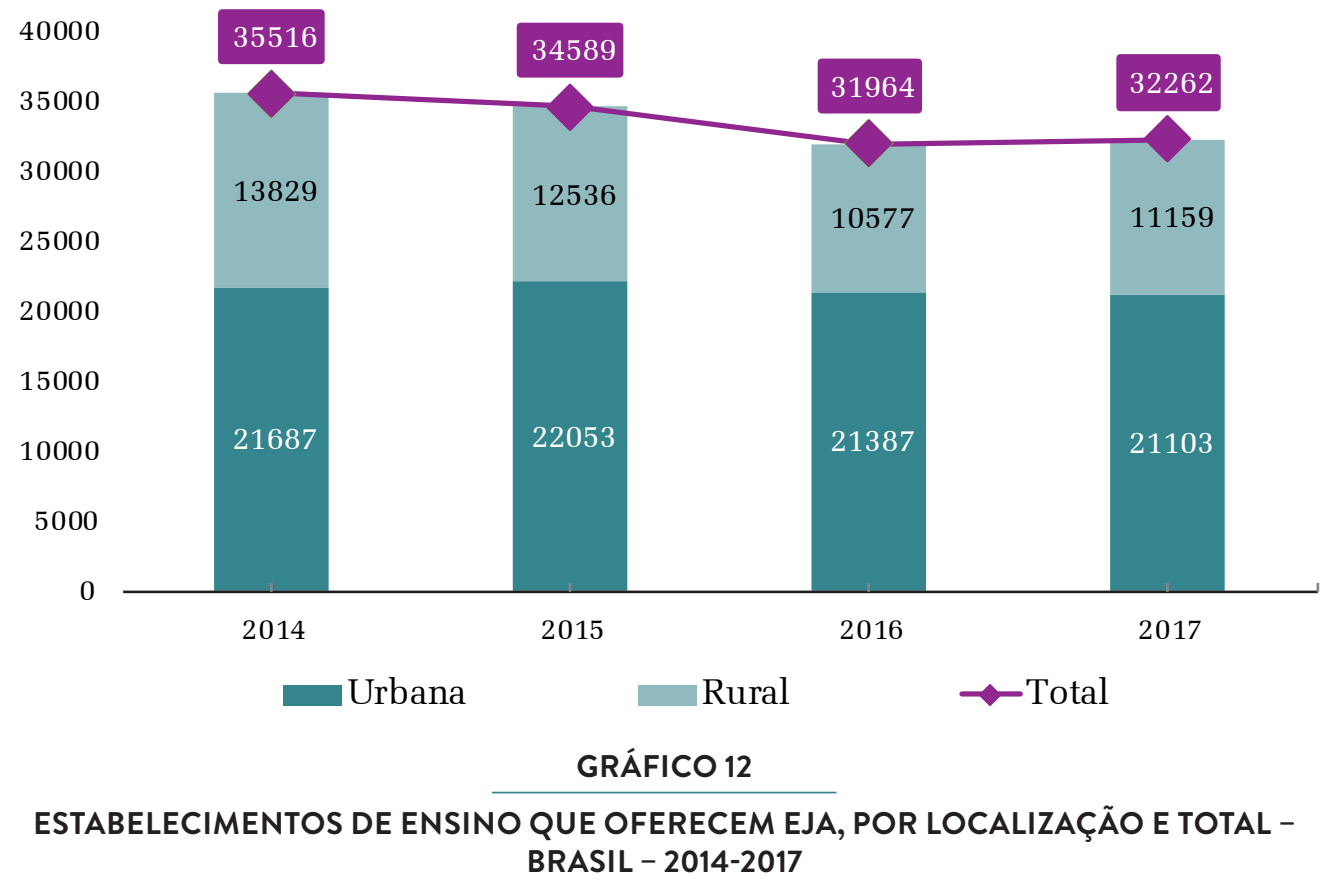

Fonte: Elaboração própria com base em dados do Censo Escolar da Educação Básica/Inep.

De modo paralelo, o número de matrículas na educação de jovens e adultos também tem se reduzido nos últimos anos, sobretudo no ensino fundamental. Após 2014, ocorreu uma ampliação no número de matrículas de EJA no ensino médio (Gráfico 13). Cabe destacar a pequena participação que as matrículas na educação profissional possuem no total de matrículas de EJA ao longo de toda a série analisada, o que impõe desafios consistentes para que se ofereçam, "no mínimo, 25\% das matrículas de educação de jovens e adultos, nos ensinos fundamental e médio, na forma integrada à educação profissional”, como preconiza a Meta 10 do PNE. 


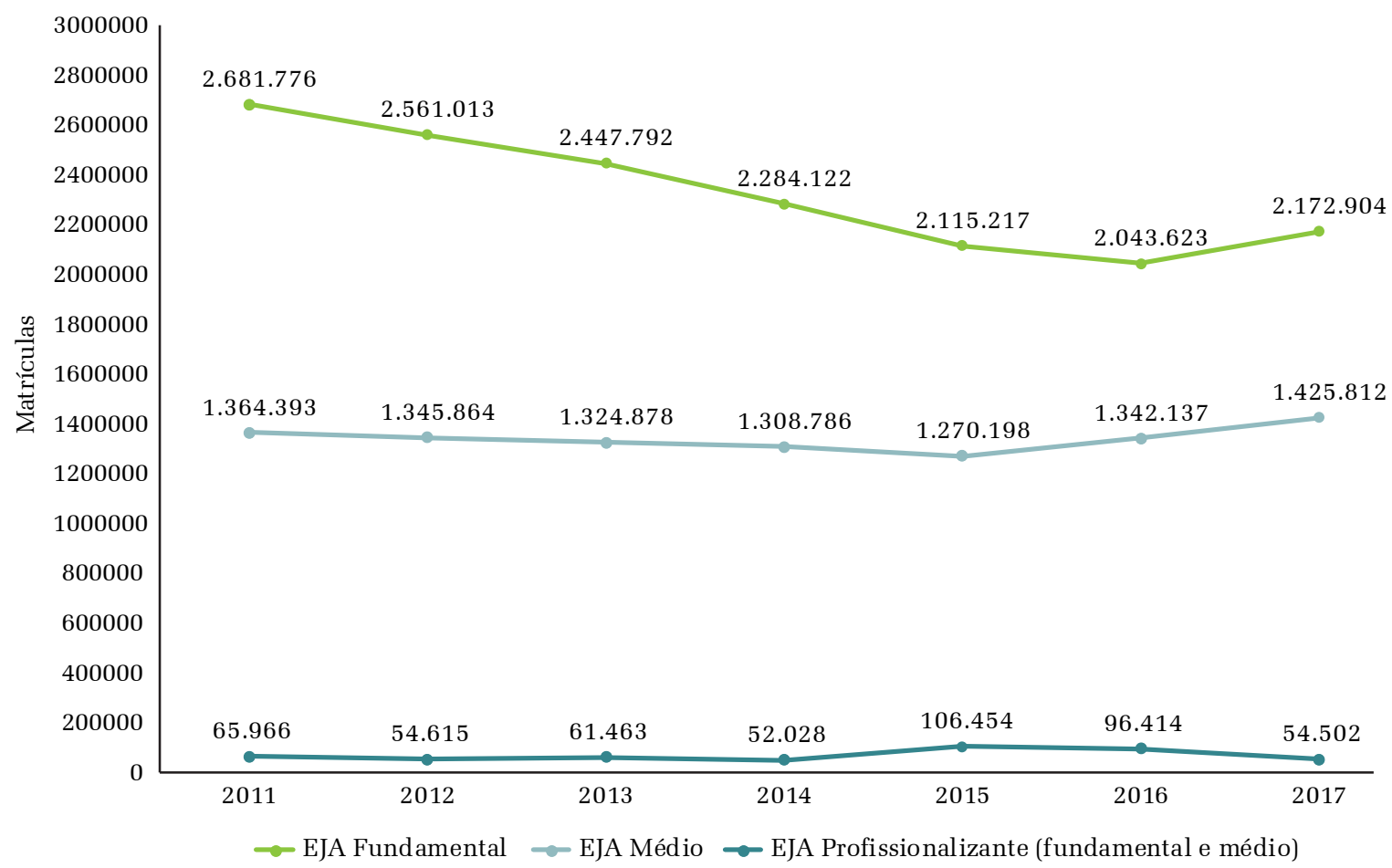

\section{GRÁFICO 13 \\ MATRÍCULAS EM CURSOS DE EJA - BRASIL - 2011-2017}

Fonte: Elaboração própria com base em dados Censo Escolar da Educação Básica e Sinopses Estatísticas (Inep).

Ao tomarmos as matrículas pela idade, nota-se uma concentração, tanto no ensino fundamental como no médio, nos grupos com idade de até 25 anos (Gráfico 14). Isso sugere a prevalência de um perfil jovem e adolescente no conjunto das matrículas, o que pode ser resultado das transições que o sistema faz entre as etapas regulares e a EJA para lidar com os problemas de fluxo dos estudantes, mas também das dificuldades maiores associadas à reinserção escolar de sujeitos que se encontram a mais tempo excluídos das instituições de ensino. Cabe ressaltar, como aponta Di Pierro (2008, p. 375), que o grupo predominante da EJA é a "juventude urbana dos setores populares que não teve êxito na escola regular e busca na EPJA um espaço de acolhida a suas características socioculturais que permita conciliar estudo e trabalho, acelerar a obtenção de certificados e/ou inserir-se em processos de qualificação profissional”. 


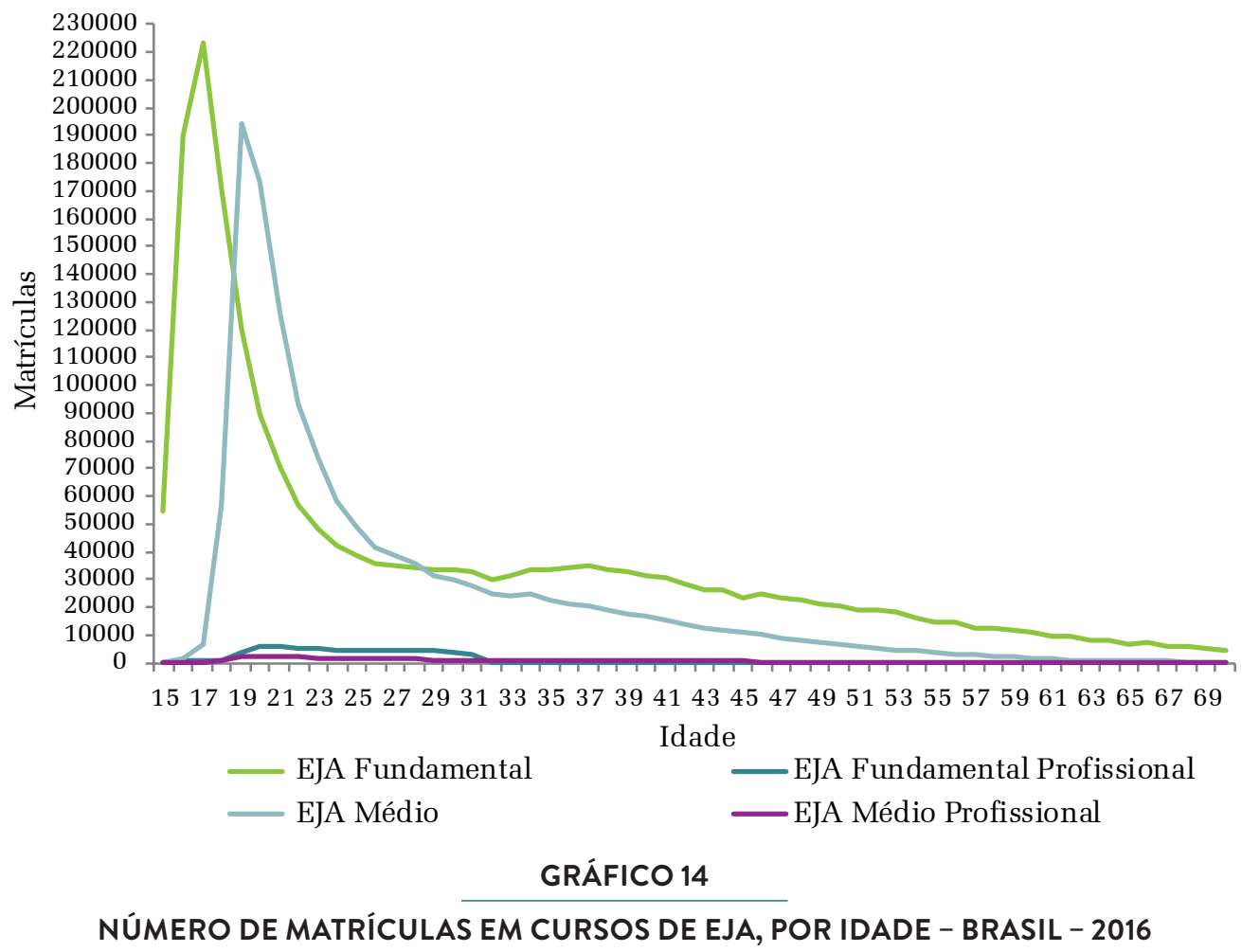

Fonte: Elaboração própria com base em dados do Censo Escolar da Educação Básica/Inep (2016).

Em adição a tais reflexões, a análise do tipo de etapa na qual a matrícula de EJA ocorre em conjunto com a média de idade aponta que, nos anos iniciais do ensino fundamental, as matrículas em EJA retratavam uma média de idade de 40,3 anos, ao passo que, nos anos finais e no ensino médio, os valores eram de 25,2 e 26,9, respectivamente (Gráfico 15). De tal modo, é importante chamar a atenção para o fato de que os grupos que ingressam no ensino fundamental e no médio da EJA concentram perfis mais jovens, enquanto os anos iniciais do ensino fundamental recebem pessoas possivelmente a mais tempo fora das instituições escolares, visto serem indivíduos em faixas etárias mais velhas.

Para retomar as discussões anteriores sobre as populações sem a educação básica completa, o Gráfico 16 mostra dados sobre o total de matrículas em EJA (fundamental e médio) em comparação com o total da população com mais de 15 anos de idade que não frequenta a escola e não possui a educação básica completa. Da Pnad são extraídas as estimativas acerca do total da população fora da escola sem a educação básica completa no ano de 2015, já do Censo Escolar foram obtidas as informações sobre o número de matrículas em EJA no ensino fundamental e no médio em 2016 (Gráfico 16). Os dados ajudam a dimensionar as distâncias entre o que é ofertado e o público potencial, além de confirmar que o "estoque” não é composto apenas por grupos com idade mais elevada, mas incluiu pessoas que frequentaram as instituições escolares em anos recentes. 


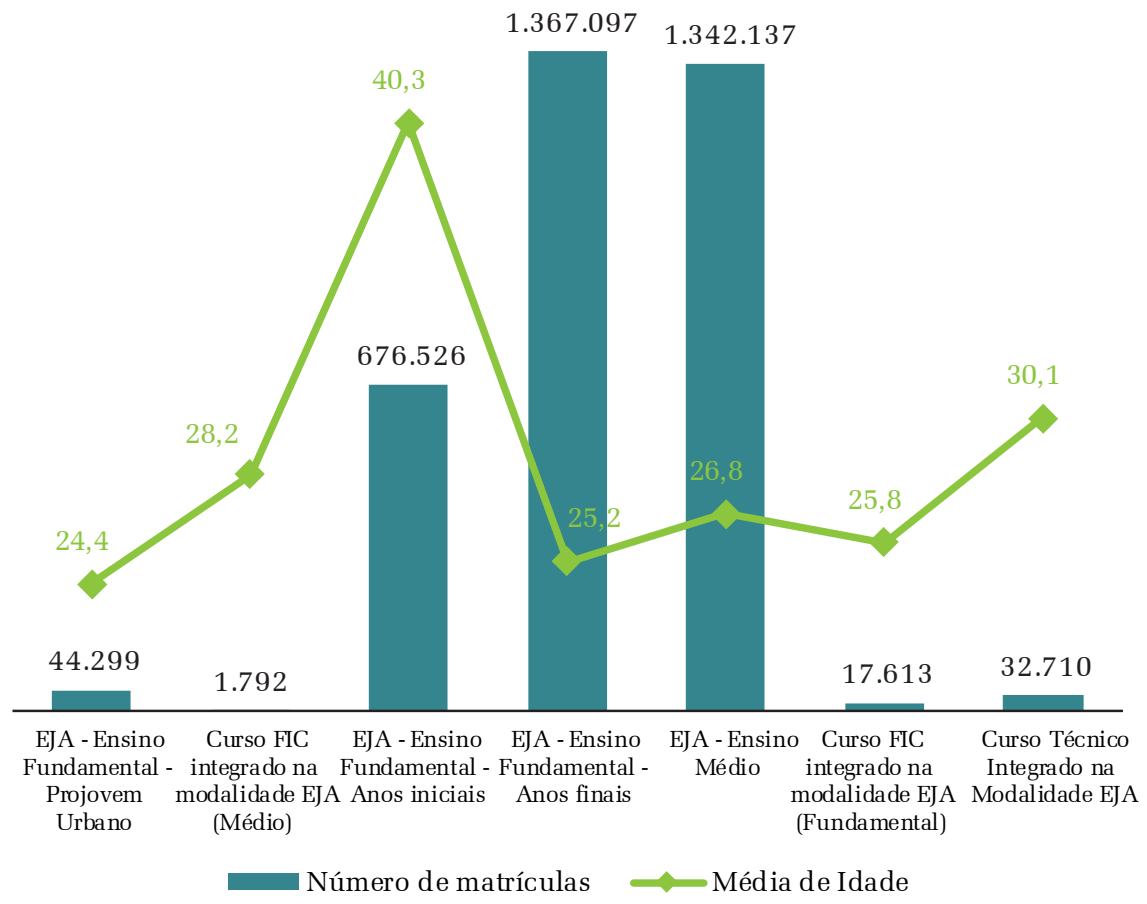

\section{GRÁFICO 15}

NÚMERO DE MATRÍCULAS E MÉDIA DE IDADE, POR TIPO DE CURSOS DE EJA - BRASIL - 2016

Fonte: Elaboração própria com base em dados do Censo Escolar da Educação Básica/Inep (2016).



Não tem Ed. Básica

$\longrightarrow$ Matrículas EJA

Matrículas EJA

e não frequenta

Fundamental

Médio

\section{GRÁFICO 16}

\section{NÚMERO DE MATRÍCULAS EM CURSOS DE EJA E TOTAL DA POPULAÇ̃̃O SEM EDUCAÇÃO BÁSICA QUE NÃO FREQUENTA A ESCOLA - BRASIL - 2016/2015}

Fonte: Elaboração própria com base em dados do Censo Escolar da Educação Básica/Inep (2016) e Pnad (2015). 


\section{DESIGUALDADES NAS CHANCES DE CONCLUSÃO DO ENSINO FUNDAMENTAL E DO MÉDIO}

Os dados expostos até aqui confirmam a permanência de trajetórias e exclusões escolares distintas para os diversos grupos sociais observados, bem como uma distância entre o número de indivíduos fora da escola sem a educação básica completa e o quantitativo de matrículas ofertadas em EJA. Considerando os indivíduos que não frequentam a escola, é importante compreender quem são aqueles com maiores chances de terem concluído o ensino fundamental ou o médio. Isso pode contribuir também com investigações posteriores sobre o que diferencia os que concluem daqueles que não concluem, de maneira a orientar políticas de garantia do direito à educação.

A análise utilizou duas variáveis dependentes categóricas: a primeira se a pessoa possuía o ensino fundamental completo (sim ou não) e a segunda se ela possuía a educação básica completa (sim ou não). Em todos os casos, foram consideradas apenas as pessoas que não estavam mais frequentando a escola, de modo que o que está sendo investigado aqui são as características que diferenciam os indivíduos que deixaram a escola tendo concluído ou não a respectiva etapa de ensino. A partir disso, foram selecionadas variáveis independentes dentre as que expressam as desigualdades socioeconômicas mais comumente diferenciadoras no acesso escolar: renda, local de residência, sexo, raça/cor e ocupação. Para concretizar o estudo, foram elaborados modelos de regressão logística binomial para estimar as desigualdades nas chances de ter o ensino fundamental ou o médio, com base nos dados da Pnad de 2015.

O primeiro modelo analisou as chances de a pessoa com idade entre 16 e 29 anos que não frequentava mais a escola ter concluído o ensino fundamental. ${ }^{10} \mathrm{Em}$ relação às desigualdades relativas ao sexo, as mulheres tinham 2,1 chances a mais de terem o ensino fundamental completo do que os homens. Já a comparação entre os residentes no campo e aqueles que viviam nas áreas urbanas indicava que os últimos tinham 2,08 chances a mais de possuírem o ensino fundamental completo do que os residentes nas áreas rurais (Tabela 2).

Os dados também apontavam desigualdades nas chances de conclusão entre brancos e negros (1,46 a mais de chances para os primeiros), assim como dos que estavam ocupados em relação aos que não estavam ocupados (Tabela 2). No tocante a esses últimos, o peso relativo do coeficiente não pode fazer esquecer que a variável

\footnotetext{
${ }^{10} \mathrm{O}$ modelo apresentou um pseudo $\mathrm{R}^{2}$ (Nagelkerke) de 0,186, o que permite afirmar que as variáveis independentes (sexo, renda, local de residência, cor/raça e ocupação) incluídas no modelo eram responsáveis por explicar $18,6 \%$ da variação nas chances de conclusão do ensino fundamental. No que se refere à colinearidade, o modelo apresentou valores de Tolerance superiores a 0 (zero) e valores de VIF abaixo de 2, o que aponta que colinearidade não afeta o modelo (Miles; Shevlin, 2011). Além disso, o modelo apresentou um percentual de classificação global de 79,2\%. Teste de Wald significativo (p-valor $>0,01)$ para todas as variáveis.
} 
dicotômica incluída no modelo engloba uma variabilidade significativa de ocupações. De todo modo, a inserção ocupacional possui efeitos positivos na explicação das chances de conclusão do ensino fundamental para o grupo de idade considerado, o que apresenta elementos importantes para análises sobre as relações entre abandono escolar e necessidade de trabalhar.

A análise do rendimento apontou a relevância das desigualdades socioeconômicas na explicação do fenômeno. Os pertencentes ao $2^{\circ}$ quintil tinham 1,57 mais chances de possuir o ensino fundamental que os integrantes do $1^{\circ}$ quintil. As desigualdades ficam mais explícitas à medida que o grupo é comparado aos de maior renda. Os oriundos do $5^{\circ}$ quintil tinham 8,33 mais chances de possuir o ensino fundamental do que os pertencentes ao $1^{\circ}$ quintil (Tabela 2).

Em síntese, as chances de ter concluído o ensino fundamental no grupo entre 16 e 29 anos que não frequentava a escola eram menores para os jovens do sexo masculino, residentes no campo, sem ocupação e com rendimentos domiciliares per capita mais reduzidos. Assim, apesar de o ensino fundamental ser obrigatório desde 1971, quando a Lei $\mathrm{n}^{\circ} 5.692$, que fixava as diretrizes e bases para o ensino de $1^{\circ}$ e $2^{\circ}$ graus, definiu em seu artigo 20 que "o ensino de $1^{\circ}$ grau será obrigatório dos 7 aos 14 anos", a exclusão persiste com maior prevalência entre alguns grupos sociais (Tabela 2).

TABELA 2

\section{COEFICIENTES DA REGRESSÃO PARA AS CHANCES DE POSSUIR O ENSINO FUNDAMENTAL COMPLETO ENTRE O GRUPO DE 16 A 29 ANOS QUE NÃO FREQUENTAVA A ESCOLA - BRASIL - 2015}

\begin{tabular}{|c|c|c|c|c|c|c|c|}
\hline & \multirow{2}{*}{ B } & \multirow{2}{*}{$\begin{array}{l}\text { Std. } \\
\text { Error }\end{array}$} & \multicolumn{2}{|c|}{ IC $95 \%$ B } & \multicolumn{3}{|c|}{ IC $95 \% \operatorname{Exp}(B)$} \\
\hline & & & Lower & Upper & $\operatorname{Exp}(B)$ & Lower & Upper \\
\hline (Intercept) & $-0,75$ & 0,051 & $-0,854$ & $-0,653$ & 0,471 & 0,426 & 0,521 \\
\hline $\begin{array}{l}\text { Sexo (feminino em relação a } \\
\text { masculino) }\end{array}$ & 0,75 & 0,026 & 0,696 & 0,799 & 2,112 & 2,006 & 2,222 \\
\hline $\begin{array}{l}\text { Localização (urbano em relação ao } \\
\text { rural) }\end{array}$ & 0,73 & 0,043 & 0,651 & 0,818 & 2,085 & 1,918 & 2,267 \\
\hline $\begin{array}{l}\text { Cor (brancos em relação aos } \\
\text { negros) }\end{array}$ & 0,38 & 0,028 & 0,323 & 0,435 & 1,461 & 1,382 & 1,545 \\
\hline Renda ( $2^{\circ}$ quintil em relação ao $1^{\circ}$ ) & 0,45 & 0,035 & 0,383 & 0,520 & 1,570 & 1,467 & 1,682 \\
\hline Renda ( $3^{\circ}$ quintil em relação ao $1^{\circ}$ ) & 0,93 & 0,040 & 0,846 & 1,004 & 2,523 & 2,331 & 2,730 \\
\hline Renda ( $4^{\circ}$ quintil em relação ao $1^{\circ}$ ) & 1,50 & 0,044 & 1,415 & 1,588 & 4,489 & 4,118 & 4,893 \\
\hline Renda ( $5^{\circ}$ quintil em relação ao $1^{\circ}$ ) & 2,12 & 0,065 & 1,992 & 2,248 & 8,335 & 7,334 & 9,473 \\
\hline $\begin{array}{l}\text { Ocupação (ocupados em relação } \\
\text { aos não ocupados) }\end{array}$ & 0,41 & 0,031 & 0,352 & 0,474 & 1,511 & 1,422 & 1,606 \\
\hline
\end{tabular}

Fonte: Elaboração própria com base em dados da Pnad/IBGE (2015).

Nota: Todos significativos ao p-valor $<0,001$. 
Na sequência, foram examinadas as desigualdades nas chances de ter concluído o ensino médio, considerando exclusivamente a população de 19 a 29 anos de idade que não frequentava mais a escola. Desse modo, o que se procura analisar são as chances de o indivíduo que não está frequentando mais a escola possuir o ensino médio. As mesmas variáveis independentes anteriormente utilizadas foram inseridas no modelo como dimensões explicativas do fenômeno relativo à conclusão do ensino médio. ${ }^{11}$

As desigualdades entre os grupos nas chances de possuir o ensino médio são parecidas com as registradas para o ensino fundamental. Em 2015, mulheres que não frequentavam a escola tinham 2,1 mais chances de já possuir o ensino médio do que os homens. Em relação à localização de residência, as chances de um jovem de 19 a 29 anos que não frequentava a escola possuir, em 2015, o ensino médio completo era 1,9 maior para os residentes nas áreas urbanas (Tabela 3).

Assim como foi observado para o ensino fundamental, brancos tinham mais chances de possuir o ensino médio: 1,4 vezes a mais que os negros. Já os que estavam ocupados possuíam, em 2015, 1,3 a mais de chances de possuir a educação básica completa do que os que não estavam ocupados (Tabela 3). Como dito anteriormente, o efeito relativamente reduzido da variável ocupação precisa considerar, em análises mais detalhadas, que ela possui uma heterogeneidade importante, incluindo desde indivíduos ocupados com carteira de trabalho assinada ou como servidores públicos, que exigem normalmente níveis mais elevados de escolarização, até aqueles que desempenhavam atividades sem vínculo formal ou para o próprio uso/consumo, incluindo atividades com pouca formalização e proteção trabalhista e as direcionadas para a subsistência.

Todavia, a variável que apresentou maior peso na explicação das variações da dependente (possuir o ensino médio) foi a relativa ao rendimento, mesma situação ocorrida na análise referente ao ensino fundamental. Os pertencentes ao $4^{\circ}$ quintil de renda tinham 4,1 chances a mais que os do $1^{\circ}$ de possuírem o ensino médio; já os oriundos do $5^{\circ}$ quintil apresentavam 8,6 vezes mais chances de possuir o ensino médio completo do que os do $1^{\circ}$ quintil (Tabela 3).

\footnotetext{
${ }^{11} \mathrm{O}$ modelo delineado apresentou um Pseudo R2 (Nagelkerke) no valor de 0,233, o que permite inferir que as variáveis independentes incluídas na análise são responsáveis por 23,3\% da variação na dependente (Tabela 3). A análise de colinearidade para o modelo com a variável dependente posse do ensino médio também apresentou valores de Tolerance superiores a 0 (zero) e valores de VIF abaixo de 2, o que permite inferir que colinearidade não afeta o modelo (Miles; Shevlin, 2011). Modelo apresentou percentual de classificação global de 70,4\%. Teste de Wald significativo (p-valor>0,01) para todas as variáveis.
} 
TABELA 3

COEFICIENTES DA REGRESSÃO PARA AS CHANCES DE POSSUIR A EDUCAÇÃO BÁSICA COMPLETA ENTRE A POPULAÇÃO DE 19 A 29 ANOS DE IDADE QUE NÃO FREQUENTAVA A ESCOLA - BRASIL - 2015

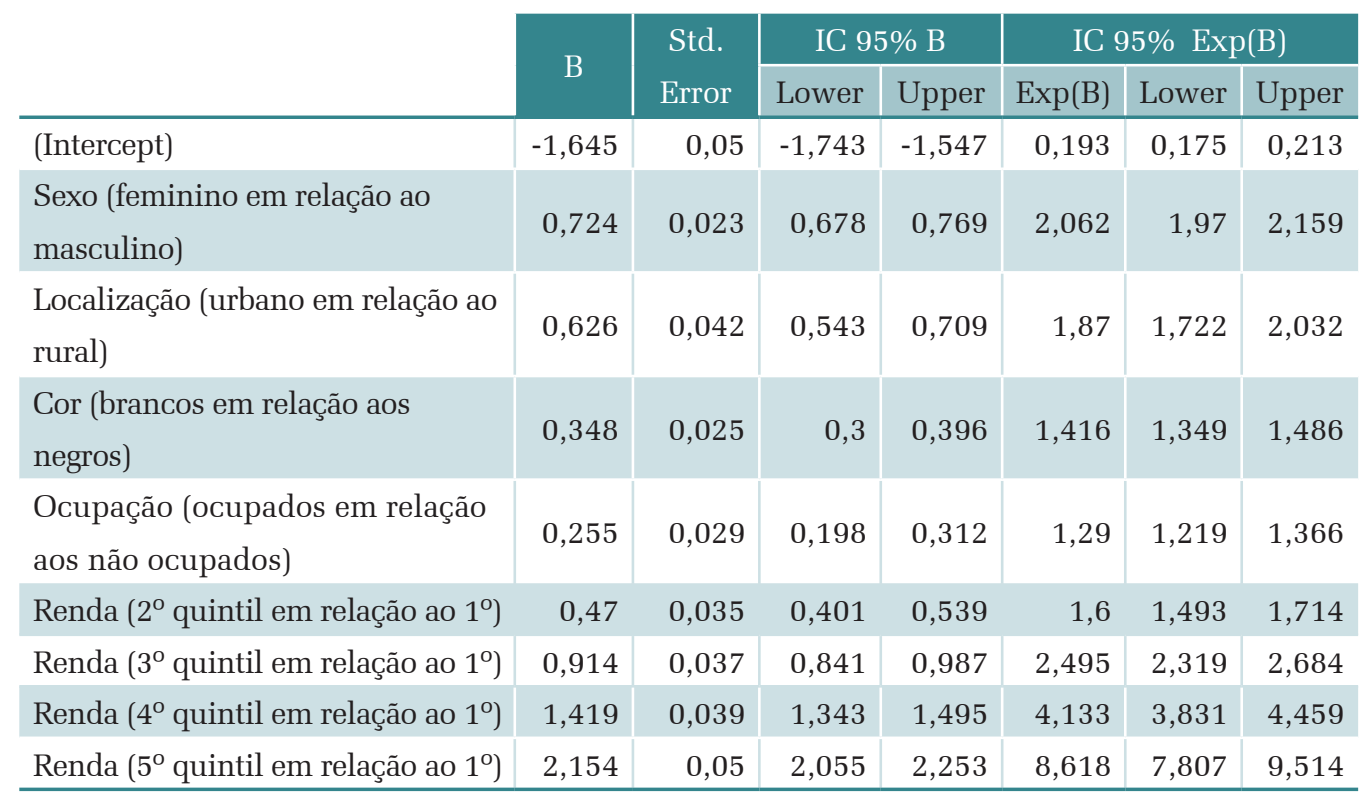

Fonte: Elaboração própria com base em dados da Pnad/IBGE (2015).

Nota: Todos significativos ao p-valor $<0,001$

\section{CONCLUSÕES}

A evasão e a exclusão escolar continuam a ocorrer mesmo entre os grupos mais jovens, de modo que as necessidades por alfabetização e ampliação da escolaridade não são restritas às coortes mais velhas. De acordo com as taxas de transição analisadas, o fenômeno prossegue reproduzindo-se entre aqueles que ingressaram nos sistemas de ensino nos anos recentes, por isso, as escolas continuam a produzir públicos para a educação de jovens e adultos. A baixa escolaridade de jovens e adultos não constitui um fenômeno tendente a desaparecer no médio prazo em função exclusiva de elementos demográficos, como o envelhecimento e a mortalidade. Diante disso, as políticas de "acompanhamento pedagógico individualizado e para recuperação e progressão parcial”, como pontua a Estratégia 8.1, podem garantir políticas de correção de fluxo.

O número de estabelecimentos de ensino que ofertam EJA diminuiu entre os anos de 2014 e 2016. Além disso, o quantitativo existente é relativamente baixo, sobretudo em comparação ao contingente social desprovido da escolarização básica. Assim, paralelamente à Estratégia 8.3, que visa "garantir acesso gratuito a exames de certificação da conclusão dos ensinos fundamental e médio”, é importante avaliar a 
necessidade de ampliar o conjunto de espaços que disponibilizam cursos adequados às formas de aprendizagem ao longo da vida.

As matrículas em EJA no ano de 2016 se concentravam, tanto para o ensino fundamental como para o médio, nas faixas etárias mais jovens. Isso pode indicar a existência de ações voltadas para a correção de fluxo dos estudantes que estão nos sistemas de ensino. Além disso, é importante analisar com mais detalhes as transições feitas pelos sistemas entre as modalidades regulares e a EJA. Entre as coortes mais velhas, dificuldades adicionais de induzir um retorno às práticas institucionais de escolarização, como configurações familiares, trabalho, dificuldades de aprendizagem, currículos e estruturas inadequadas, entre outros fatores, podem ajudar a explicar a menor participação dos segmentos mais velhos no número de matrículas.

Os percentuais de jovens sem o ensino fundamental ou o médio completo são maiores entre os residentes no campo, os mais pobres, os do sexo masculino e os negros. A reprodução desses perfis como aqueles que frequentemente são os mais excluídos do sistema educacional oferece um caráter "repetitivo" aos dados. Por isso, é fundamental compreender a manutenção de situações extra e intraescolares que reproduzem tais grupos como os "personagens" predominantes da exclusão escolar. Justamente em função dessas características, a Estratégia 8.2 propõe "implementar programas de educação de jovens e adultos para os segmentos populacionais considerados, que estejam fora da escola e com defasagem idade-série, associados a outras estratégias que garantam a continuidade da escolarização, após a alfabetização inicial”.

As Metas 8 e 9 ressaltam a necessidade de que sejam adotadas ações de busca ativa, permitindo que os jovens e adultos com baixa escolaridade sejam identificados e retornem aos estudos. Imbricado a isso, é fundamental a realização do "diagnóstico dos jovens e adultos com ensino fundamental e médio incompletos, para identificar a demanda ativa por vagas na educação de jovens e adultos”, tal como propõe a Estratégia 9.2.

Em adição a conclusões anteriores, considerando os que não frequentam mais a escola, a comparação nas chances de conclusão do ensino fundamental e do médio permitiu compreender que, apesar de melhoras observadas no acesso à escola, mantêm-se as situações desiguais nas oportunidades educacionais, em prejuízo dos mesmos grupos sociais já mapeados pela literatura: jovens do sexo masculino, negros, residentes no campo, sem ocupação e, sobretudo, os de menor rendimento. Tais constatações, que já se tornaram rotineiras, denotam que o acesso e a conclusão escolar seguem sendo menos prováveis entre os "esperados de sempre", o que ressalta a relevância das desigualdades existentes no desenho das políticas públicas de educação de jovens e adultos. Entender as circunstâncias que continuam a fazer com que as expectativas de exclusão de determinados sujeitos se confirmem constitui o desafio central para as análises e para o monitoramento das Metas 8, 9 e 10 do PNE. 


\section{REFERÊNCIAS}

ARROYO, M. Outros sujeitos, outras pedagogias. Petrópolis: Vozes, 2012.

BARROS, R. P.; MENDONÇA, R. S. P. Os determinantes da desigualdade no Brasil. Brasília: IPEA, 1995. (Texto para Discussão; n. 377).

BOURDIEU, P. Meditações pascalinas. Rio de Janeiro: Bertrand Brasil, 2001.

BRASIL. (Constituição 1988). Emenda Constitucional no 59, de 11 de novembro de 2009. Acrescenta $\S 3^{\circ}$ ao art. 76 do Ato das Disposições Constitucionais Transitórias para reduzir, anualmente, a partir do exercício de 2009, o percentual da Desvinculação das Receitas da União incidente sobre os recursos destinados à manutenção e desenvolvimento do ensino de que trata o art. 212 da Constituição Federal, dá nova redação aos incisos I e VII do art. 208, de forma a prever a obrigatoriedade do ensino de quatro a dezessete anos e ampliar a abrangência dos programas suplementares para todas as etapas da educação básica, e dá nova redação ao $\S 4^{\circ}$ do art. 211 e ao $\S 3^{\circ}$ do art. 212 e ao caput do art. 214, com a inserção neste dispositivo de inciso VI. Diário Oficial da União, Brasília, DF, 12 nov. 2009.

Seção 1, p. 8.

BRASIL. Lei $\mathrm{n}^{\circ}$ 5.692, de 11 de agosto de 1971. Fixa Diretrizes e Bases para o ensino de $1^{\circ}$ e $2^{\circ}$ graus, e dá outras providências. Diário Oficial da União, Brasília, DF, 12 ago. 1971. Seção 1, p. 6377.

BRASIL. Lei $\mathrm{n}^{\circ}$ 9.394, de 20 de dezembro de 1996. Estabelece as diretrizes e bases da educação nacional. Diário Oficial da União, Brasília, DF, 23 dez. 1996. Seção 1, p. 27833.

BRASIL. Lei $\mathrm{n}^{\mathrm{O}}$ 13005, de 25 de junho de 2014. Aprova o Plano Nacional de Educação - PNE e dá outras providências. Diário Oficial da União, Brasília, DF, 26 jun. 2014. Seção 1, p. 1.

BRASIL. Instituto Nacional de Estudos e Pesquisas Educacionais Anísio Teixeira (Inep). Relatório do $1^{o}$ ciclo de monitoramento das metas do PNE: biênio 2014-2016. Brasília: Inep, 2016.

BRASIL. Instituto Nacional de Estudos e Pesquisas Educacionais Anísio Teixeira (Inep). Nota Técnica $n^{o}$ 8, de 27 de junho de 2017. Estimativas de fluxo escolar a partir do acompanhamento longitudinal dos registros de aluno do Censo Escolar no período 2007 - 2016. Brasília: Inep, 2017. 
CONFERÊNCIA INTERNACIONAL DE EDUCAÇÃO DE ADULTOS (Confitea), 6. 2010, Belém. Marco de ação de Belém. Brasília: Unesco, 2010.

CURY, C. R. J. A educação básica como direito. Cadernos de Pesquisa, São Paulo, v. 38, n.134, p. 293-303, maio/ago. 2008.

DAHL, R. Sobre a democracia. Tradução de Beatriz Sidou. Brasília: EdUnB, 2001.

DELORS, J. Educação: um tesouro a descobrir: relatório para a UNESCO da Comissão Internacional sobre Educação para o século XXI. São Paulo: Cortez, 1996.

DI PIERRO, M. C. Educação de jovens e adultos na América Latina e Caribe: trajetória recente. Cadernos de Pesquisa, São Paulo, v. 38, p. 367-391, maio/ago. 2008.

DI PIERRO, M. C. Educação de Jovens e Adultos. In: OLIVEIRA, D. A.; DUARTE, A. M. C.; VIEIRA, L. M. F. Dicionário: trabalho, profissão e condição docente. Belo Horizonte: UFMG/Faculdade de Educação, 2010.

HAIR, J. et al. Análise multivariada de dados. 6. ed. Porto Alegre: ARTMED, 2009.

KRAWCZYK, N. Reflexão sobre alguns desafios do ensino médio no Brasil hoje. Cadernos de Pesquisa, São Paulo, v. 41, n. 144, p. 752-769, set./dez. 2011.

FÁVERO, L. P.; BELFIORE, P. Manual de análise de dados. Rio de Janeiro: Elsevier, 2017.

FRASER, N. Reenquadrando a justiça em um mundo globalizado. Lua Nova, São Paulo, n. 77, p. 11-39, 2009.

HOSMER, D. W.; LEMESHOW, S. Applied Logistic Regression. 2. ed. New York: JW, 2000.

LIMA, L. C. A EJA no contexto de uma educação permanente ou ao longo da vida: mais humanos e livres, ou apenas mais competitivos e úteis? In: BRASIL. Ministério da Educação (MEC). Coletânea de textos CONFINTEA Brasil+6: tema central e oficinas temáticas. Brasília: MEC, 2016. p. 15-25.

MACHADO, M. M.; RODRIGUES, M. E. C. Educação de jovens e adultos - relação educação e trabalho. Revista Retratos da Escola, Brasília, v. 7, n. 13, p. 373-385, jul./dez. 2013.

MARTINS JÚNIOR, J. P.; DANTAS, H. O índice de participação e a importância da educação. Revista Opinião Pública, Campinas, v. 10, n. 2, p. 268-287, out. 2004. 
MILES; J.; SHEVLIN, M. Applying regression \& correlation: a guide for students and researchers. London: SAGE, 2011.

NAKANO, M.; ALMEIDA, E. Reflexões acerca da busca de uma nova qualidade da educação: relações entre juventude, educação e trabalho. Educação e Sociedade, Campinas, v. 28, n. 100, p. 1085-1104, out. 2007.

NERI, M. (Coord.). Motivos da evasão escolar. Rio de Janeiro: FGV/IBRE/ CPS, 2009. Disponível em: < http://www.cps.fgv.br/ibrecps/rede/finais/Etapa3-Pesq MotivacoesEscolares_sumario_principal_anexo-Andre_FIM.pdf $>$. Acesso em: 28 ago. 2017.

PEUGNY, C. O destino vem do berço?: desigualdades e reprodução social. Campinas: Papirus, 2014.

RIBEIRO, C. A. C. Estrutura de classe e mobilidade social no Brasil. Bauru: Edusc, 2007.

RIBEIRO, C. A. C. Desigualdade de oportunidades e resultados educacionais no Brasil. Dados, Rio de Janeiro, v. 54, n. 1, p. 41-87, 2011.

RIBEIRO, S. C. A pedagogia da repetência. Revista Estudos de Avaliação, São Paulo, v. 5, n. 12, p. 7-21, maio/ago. 1991.

ROCHA, S. A inserção dos jovens no mercado de trabalho. Caderno RH, Salvador, v. 21, n. 54, p. 533-550, set./dez. 2008.

SANTOS, R. Trabalho e educação entre jovens de 15 a 29 anos residentes no campo: desafios à ampliação da escolaridade. Revista Brasileira de Estudos Pedagógicos, Brasília, v. 98, n. 250, p. 596-623, 2017.

SILVA, J. L.; BONAMINO, A. M. C.; RIBEIRO, V. M. Escolas eficazes na educação de jovens e adultos: estudo de casos na rede municipal do Rio de Janeiro. Educação em Revista, Belo Horizonte, v. 28, n. 2, p. 367-392, jun. 2012.

SILVA, P. L. N.; PESSOA, D. G. C.; LILA, M. F. Análise estatística de dados da PNAD: incorporando a estrutura do plano amostral. Revista Ciência e Saúde Coletiva, Rio de Janeiro, v. 7, n. 4, p. 659-670, 2002.

SIMÕES, A. A. As metas de universalização da Educação Básica no Plano Nacional de Educação: o desafio do acesso e a evasão dos jovens de famílias de baixa renda no Brasil. Brasília: Inep, 2016. (PNE em Movimento; n. 4).

SOARES, T. M. et al. Fatores associados ao abandono escolar no ensino médio público 
de Minas Gerais. Educação e Pesquisa, São Paulo, v. 41, n. 3, p. 757-772, set. 2015.

TORRES, C. A. Political sociology of adult education. Rotterdam: Sense Publishers, 2013.

ORGANIZAÇÃO DAS NAÇÕES UNIDAS PARA A EDUCAÇÃO, A CIÊNCIA E A CULTURA (Unesco). Terceiro relatório global sobre aprendizagem e educação de adultos: o impacto da aprendizagem e da educação de adultos na saúde e no bem-estar, no emprego e no mercado de trabalho e na vida social, cívica e comunitária. Brasília: Unesco, 2016.

ORGANIZAÇÃO DAS NAÇÕES UNIDAS PARA A EDUCAÇÃO, A CIÊNCIA E A CULTURA (Unesco). Recommendations on the development of adult education: adopted by the General Conference at its nineteenth session Nairobi, 26 November 1976. Paris: Unesco, 1976.

VALDÉS, R. et al. (Coord). Contribuições conceituais da educação de pessoas jovens e adultas: rumo à construção de sentidos comuns na diversidade. Tradução de Daniele Martins e Zenaide Romanovsky. Goiânia: Ed. UFG, 2014.

ZAGO, N. Migração rural-urbana, juventude e ensino superior. Revista Brasileira de Educação, Rio de Janeiro, v. 21, n. 64, p. 61-78, mar. 2016. 